Aus der Klinik für Neurochirurgie

(Prof. Dr. med. V. Rohde)

der Medizinischen Fakultät der Universität Göttingen

\title{
Anlage von Lysekathetern zur rtPA- Lysetherapie von intrazerebralen
}

\section{Hämatomen}

Führt die zentrale Lage des Lysekatheters zur effektiveren Hämatomlyse?

\author{
INAUGURAL-DISSERTATION \\ zur Erlangung des Doktorgrades \\ der Medizinischen Fakultät der \\ Georg-August-Universität zu Göttingen
}

vorgelegt von

Anna Schlegel

aus

Bremen

Göttingen 2020 
Dekan:

Referent/in

Ko-Referent/in:

Drittreferent/in:

Datum der mündlichen Prüfung:
Prof. Dr. med. W. Brück

Prof. Dr. med. D. Mielke 
Hiermit erkläre ich, die Dissertation mit dem Titel "Anlage von Lysekathetern zur rtPA-Lysetherapie von intrazerebralen Hämatomen - Führt die zentrale Lage des Lysekatheters zur effektiveren Hämatomlyse?" eigenständig angefertigt und keine anderen als die von mir angegebenen Quellen und Hilfsmittel verwendet zu haben.

Göttingen, den 
Die Daten, auf denen die vorliegende Arbeit basiert, wurden teilweise publiziert:

Malinova V, Schlegel A, Rohde V, Mielke D (2017): Catheter placement for lysis of spontaneous intracerebral hematomas: does a catheter position in the core of the hematoma allow more effective and faster hematoma lysis? Neurosurg Rev, $40 \underline{3}$, 397402

Iliev B, Schlegel A, Mielke D, Rohde V, Malinova V (2019): Intrahematomal catheter placement with connection to the ventricular system allows more effective thrombolysis of combined intracerebral and intraventricular hematomas. Neurosurg Rev (im Druck) 


\section{Inhaltsverzeichnis}

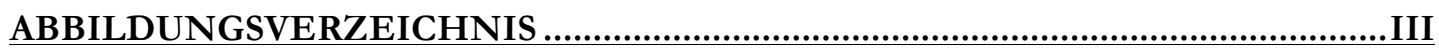

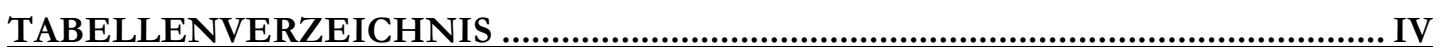

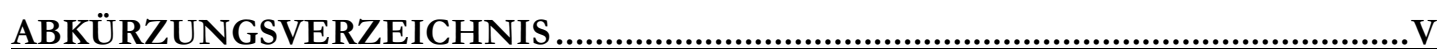

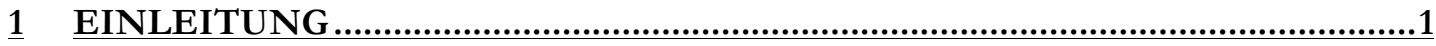

1.1 DEFINITION DER INTRAZEREBRALEN BLUTUNG...................................................

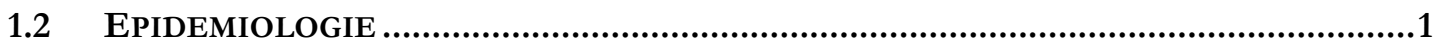

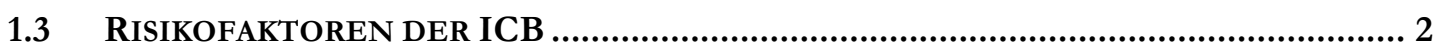

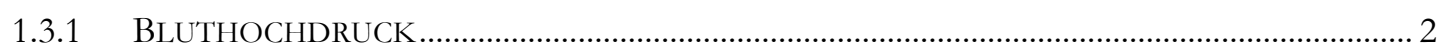

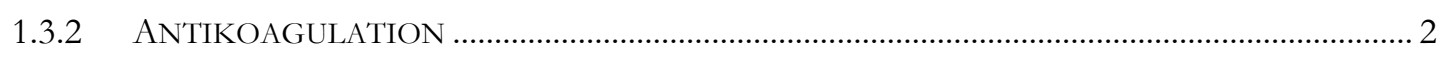

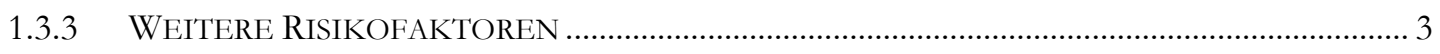

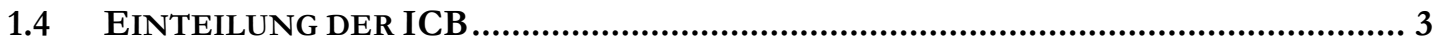

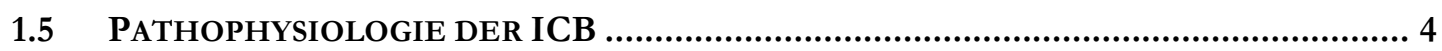

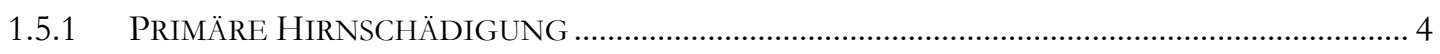

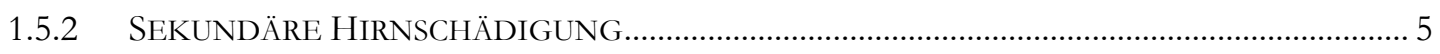

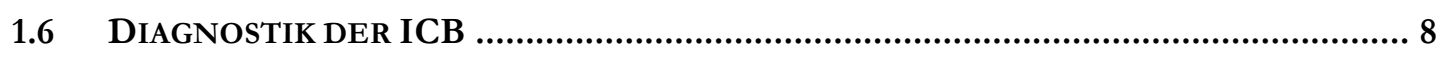

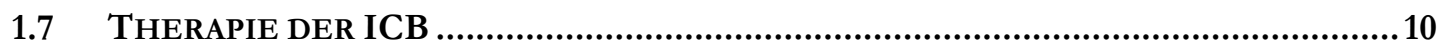

1.7.1 InITIALE VERSORgUNG VON PATIENTEN MIT EINER ICB _................................................ 10

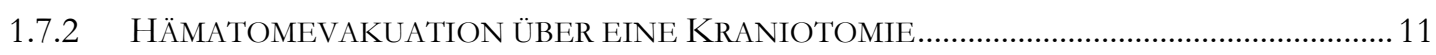

1.7.3 MinimaLINVASIVE CHIRURGIE (MIS), LYSEKATHETERANLAGE MIT ANSCHLIEBENDER

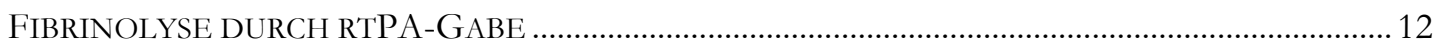

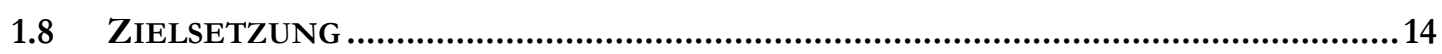

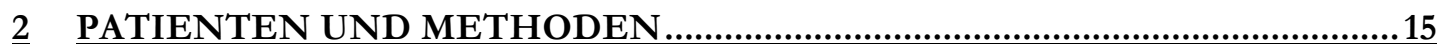

2.1 STUDIENDESIGN UND PATIENTENKOLLEKTIV ..........................................................

2.1.1 DATENERHEBUNG UND CHIRURGISCHES VERFAHREN .................................................. 16

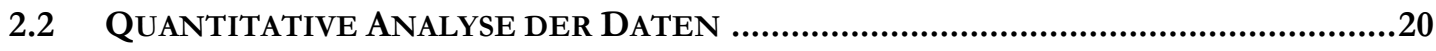

2.2.1 KATHETERPOSITION UND RELATIVE ERROR (RE) _........................................................ 20

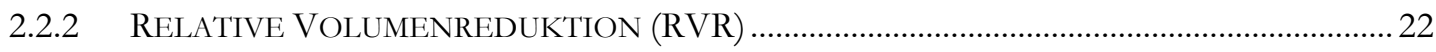

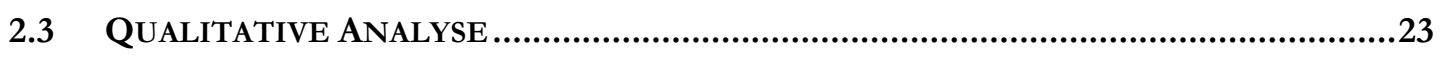

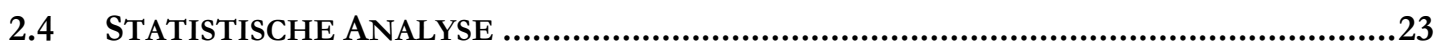


2.5 Die Glasgow-Coma-SKala (GCS)

2.6 DiE GLASGOW-OUTCOME-SKALA (GOS), BEWERTUNGSSKALA NACH

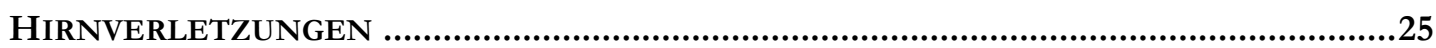

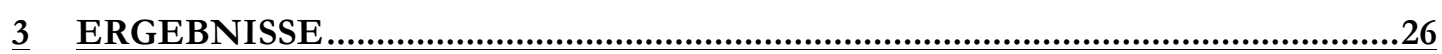

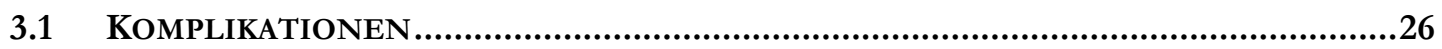

3.2 ERGEBNISSE DER QUANTITATIVEN ANALYSE....................................................28

3.3 ERGEBNISSE DER QUALITATIVEN ANALYSE ..........................................................

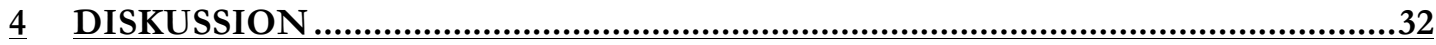

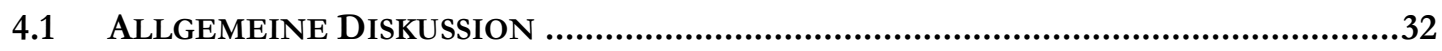

4.2 DER EINFLUSS DER KATHETERLAGE AUF DIE HÄMATOMLYSE ............................34

4.3 DER EINFLUSS DER KATHETERLAGE UND DES HÄMATOMVOLUMENS AUF DAS

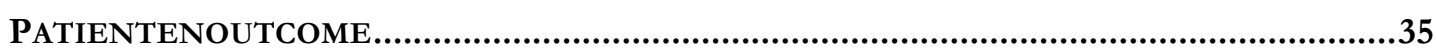

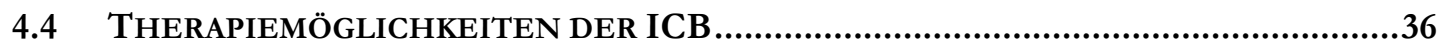

4.4.1 EVAKUATION DER ICB ÜBER EINE KRANIOTOMIE ………………………...................... 36

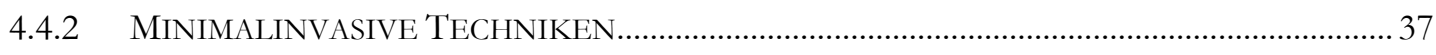

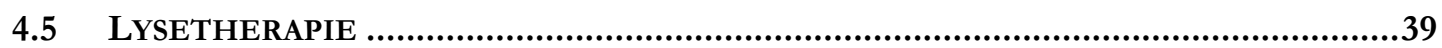

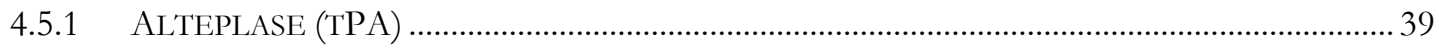

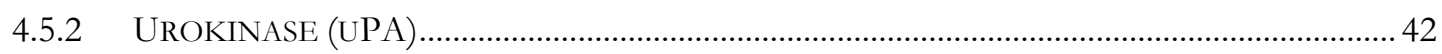

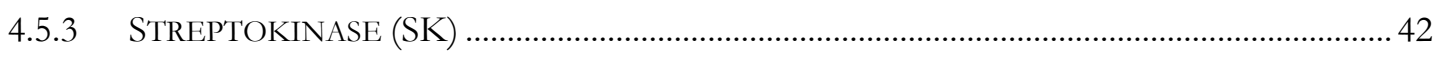

4.6 WEITERE FAKTOREN, DIE MÖGLICHE AUSWIRKUNGEN AUF DIE EFFEKTIVITÄT

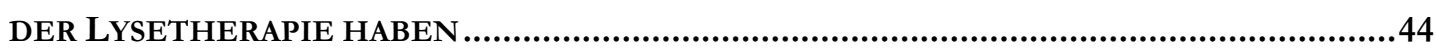

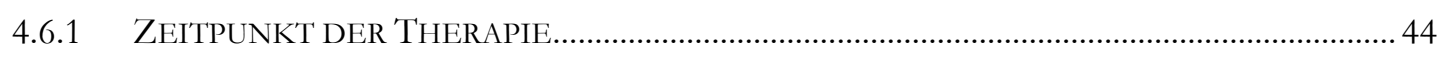

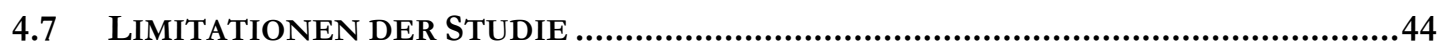

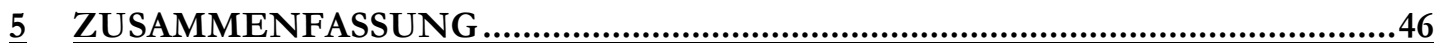

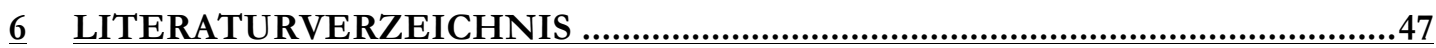




\section{Abbildungsverzeichnis}

ABbildung 1: SCHEMATISCHE DARSTELLUNG DER MECHANISMEN, WELCHE ZUR ENTWICKLUNG EINES

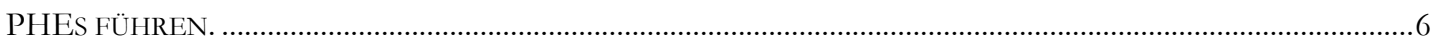

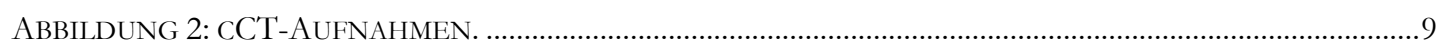

ABBILDUNG 3: KATHETER MIT HÜLSE UND NAVIGIERTEM STYLET.............................................................. 17

ABBILDUNG 4: OPERATIVES SETTING MIT EINFÜHRUNG DES LYSEKATHETERS ÜBER DIE HÜLSE UND

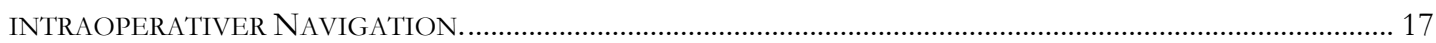

ABbildung 5: Postoperative CT-AUfNAHME MIT LySEKATHETER IN ZENTRALER LAGE..................... 18

ABbildung 6: Postoperative CT-AufNAHME Mit LYSEKATHETER IN RANDSTÄNDigER LAGE UND

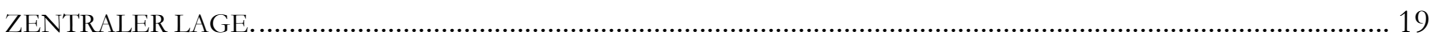

ABBILDUNG 7: EXEMPLARISCH EINE REIHE VON POSTOPERATIVEN CT BILDERN EINER ICB NACH

KATHETERANLAGE UND BEARBEITUNG MIT DEM BRAINLAB ${ }^{\odot}$-PROGRAMM............................................. 21

ABBILDUNG 8: BERECHNUNG UND BEREICH DES RE....................................................................................... 22

ABBILDUNG 9: KORRELATION ZWISCHEN RVR UND RE ................................................................................. 29

ABBILDUNG 10: DiE RVR EINES HÄMATOMS UNTER LYSETHERAPIE MIT ZENTRALER KATHETERLAGE 31

ABBILDUNG 11: DIE RVR BEI RANDSTÄNDIGER KATHETERLAGE ................................................................. 31 


\section{Tabellenverzeichnis}

TABELLE 1: ZUSAMMENFASSUNG DER KLINISCHEN PATIENTENDATEN ....................................................... 20

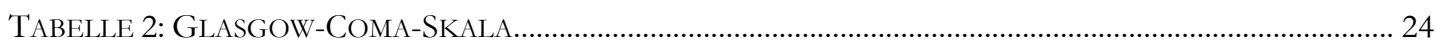

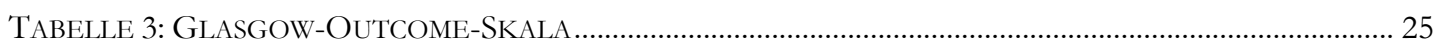

TABELLE 4: ZuSAMMENFASSUNG DER PATIENTENCHARAKTERISTIKA UND ERGEBNISSE........................... 27

TABELLE 5: DARSTELLUNG DES ZuSAMMENHANGS ZWISCHEN RE UND HÄMATOMVOLUMINA................ 28

TABELLE 6: ZUSAMMENHANG ZWISCHEN HÄMATOMVOLUMINA, KATHETERLAGE UND

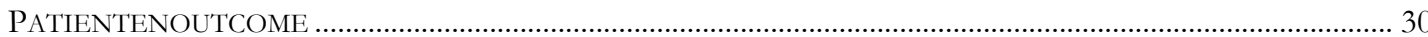




\section{Abkürzungsverzeichnis}

\begin{tabular}{|c|c|}
\hline ASA & American Stroke Association \\
\hline AVM & arteriovenöse Malformation \\
\hline CLEAR IVH & clot lysis: evaluating accelerated resolution of IVH \\
\hline CT & Computertomographie \\
\hline CTA & CT-Angiographie \\
\hline DSA & digitale Subtraktionsangiografie \\
\hline EVD & extraventrikuläre Drainage \\
\hline GBD & Global Burden of Disease \\
\hline GCS & Glasgow-Coma-Skala \\
\hline GOS & Glasgow-Outcome-Skala \\
\hline ICB & intrazerebrale Blutung \\
\hline ICP & intracerebral pressure \\
\hline INTERACT & intensive blood pressure reduction in acute cerebral hemorrbage trial \\
\hline IVB & intraventrikuläre Blutung \\
\hline IVH & intraventricular hemorrbage \\
\hline MIS & minimally invasive surgery \\
\hline mRS & modifizierte Rankin Skala \\
\hline MRT & Magnetresonanztomografie \\
\hline MISTICH & $\begin{array}{l}\text { minimally invasive surgery treatment for the patients with spontaneous supratentorial } \\
\text { intracerebral bemorrhage }\end{array}$ \\
\hline MISTIE & minimally invasive surgery plus rt-P A for ICH evacuation \\
\hline MRA & Magnetresonanzangiographie \\
\hline NOAK & neue orale Antikoagulanzien \\
\hline NSAR & nichtsteroidale Antirheumatika \\
\hline OAK & orale Antikoagulanzien \\
\hline PET & Positronenemissionstomografie \\
\hline RE & relative error \\
\hline $\mathrm{rtPA}$ & recombinant tissue plasminogen activator \\
\hline RVR & relative Volumenreduktion \\
\hline SK & Streptokinase \\
\hline STICH & international surgical trial in intracerebral hemorrhage \\
\hline SWITCH & $\begin{array}{l}\text { swiss trial of decompressive craniectomy versus best medical treatment of } \\
\text { spontaneous supratentorial intracerebral hemorrhage }\end{array}$ \\
\hline TIA & transitorisch ischämische Attacke \\
\hline uPA & urokinase-type plasminogen activator \\
\hline
\end{tabular}




\section{$1 \quad$ Einleitung}

\subsection{Definition der intrazerebralen Blutung}

Eine intrazerebrale Blutung (ICB) ist eine Blutung in das Hirnparenchym, welche spontan oder traumatisch auftreten kann. Differentialdiagnostisch zu einer Subarachnoidalblutung ( $\mathrm{SAB}$ ) oder einer intraventrikulären Blutung (IVB), ist der Subarachnoidalraum bzw. das Ventrikelsystem von der Blutung primär nicht betroffen, wobei sie sich in beide Räume sekundär ausbreiten kann (Qureshi et al. 2001b).

\subsection{Epidemiologie}

Die jährliche Schlaganfallinzidenz inklusive der transitorischen ischämischen Attacke (TIA) liegt in Deutschland derzeit bei etwa 250 pro 100.000 Einwohner, wobei durch den demographischen Wandel in den nächsten 30 Jahren ein deutlicher Anstieg der Zahlen zu erwarten ist (Foerch et al. 2008). Nach letzten Schätzungen der Global Burden of Disease (GBD) ist der Schlaganfall im Jahr 2015 mit 5,2 Millionen Toten weltweit die zweithäufigste Todesursache (Group 2017). In die Schlaganfallstatistik gehen ischämische sowie hämorrhagische Schlaganfälle ein, wobei der prozentuale Anteil der durch ICBs verursachten Schlaganfälle je nach Studie zwischen 10\% und 20\% variiert (Kolominsky-Rabas et al. 1998; Neuberger et al. 2017; Sacco et al. 1998). Gemäß einer 2010 veröffentlichten Metaanalyse basierend auf 36 Studien zwischen 1983 und 2006 mit insgesamt 8145 eingeschlossenen Patienten waren Männer und Frauen ungefähr gleich häufig von einer ICB betroffen. Bei Menschen asiatischer Abstammung war die Inzidenz in etwa doppelt so hoch (51,8 von 100.000 Einwohnern/Jahr) im Vergleich zu anderen ethnischen Gruppen (19,6-24,2 pro 100.000 Einwohnern/Jahr). Die Inzidenz der ICB steigt ebenfalls mit höherem Alter von $0,10 \%$ bei unter 45 -Jährigen bis $9,6 \%$ bei über 85-Jährigen (van Asch et al. 2010).

Die Mortalität von Patienten mit einer ICB liegt bei 45-50\% innerhalb der ersten 30 Tage und bei 60\% innerhalb eines Jahres nach Eintritt des Blutungsereignisses. Folglich ist sie deutlich höher als beim ischämischen Schlaganfall, dessen Gesamtletalität bei ca. 
13\% liegt (Hemphill et al. 2001; Sacco et al. 2009; Vila-Corcoles et al. 2014). Konsequenterweise hat die Forschung über mögliche Interventionsmöglichkeiten bei Patienten mit ICB in den letzten Jahren zunehmend an Bedeutung gewonnen. Es gilt die bestmögliche Therapie zu eruieren, um die Mortalität der Patienten zu senken und die Prognose zu verbessern (Hemphill et al. 2015).

\subsection{Risikofaktoren der ICB}

\subsubsection{Bluthochdruck}

Der Hauptrisikofaktor einer spontanen ICB ist der arterielle Hypertonus. Elektronenmikroskopische Untersuchungen aus den 80er Jahren zeigten, dass es durch die chronische Druckbelastung der Gefäße zu arteriosklerotischen Degenerationen der Tunica Media und der glatten Muskulatur kommt, wodurch die Wahrscheinlichkeit einer Ruptur steigt (Takebayashi und Kaneko 1983). Patienten mit einem Hypertonus Grad 3 (>180/110 mmHg) haben im Vergleich zu Menschen mit einem normalen Blutdruck ein über fünffach erhöhtes Risiko eine Hirnblutung zu erleiden (Sturgeon et al. 2007). Bei 45-64\% der Patienten mit ICB war in der Vorgeschichte ein arterieller Hypertonus bekannt (Brott et al. 1986; Foulkes et al. 1988). Gefährdet sind insbesondere Patienten mit unbehandeltem Hypertonus. Rund ein Viertel aller hämorrhagischen Schlaganfälle könnte durch einen gut eingestellten Bluthochdruck verhindert werden, wie eine retrospektive Analyse aus dem Jahr 2004 von Woo et al. bestätigt hat (Woo et al. 2004).

\subsubsection{Antikoagulation}

Des Weiteren kann die Einnahme von Antikoagulanzien das Risiko des Auftretens einer ICB erhöhen. Bei Patienten, die mit Vitamin-K-Antagonisten (z. B. Phenprocoumon oder Warfarin) behandelt werden, beträgt das Risiko für eine ICB 0,2\% pro Jahr (Shoeb und Fang 2013). Fang et al. (2007) untersuchten retrospektiv die extra- und intrakraniellen Blutungsrisiken bei 13.559 Patienten mit Vorhofflimmern unter Warfarin-Therapie Mitte der 1990er Jahre. In dem untersuchten Zeitraum erlitten 51 der Patienten eine ICB $(0,38 \%)$. Die Todesursache war bei 40 Patienten mit der Einnahme von Warfarin assoziiert, in $88 \%$ ist die warfarinassoziierte ICB ursächlich gewesen. Aus diesem Grund sollte die Rezeptierung von Antikoagulation sorgsam abgewogen werden (Fang et al. 2007). Im Vergleich zur Warfarin-Therapie wird durch die Einnahme von neuen oralen 
Antikoagulanzien (NOAKs, hier Rivaroxaban, Dabigatran, Apixaban, Edoxaban) laut einer Metaanalyse von 2014 mit über 70.000 Patienten das Risiko einer ICB um die Hälfte $(\mathrm{RR} 0,49)$ sowie die allgemeine Mortalität um 10\% verringert. Allerdings wurde unter der NOAK-Therapie ein Anstieg von gastrointestinalen Blutungen beobachtet (Ruff et al. 2014).

Die Einnahme von niedrigdosiertem (75-325 mg/Tag) ASS (Acetylsalicylsäure) oder von anderen nichtsteroidalen Antirheumatika (NSAR) kann das Risiko für eine ICB leicht erhöhen. 2016 wurde dazu eine Metaanalyse von sieben Studien veröffentlicht, die im Gesamtergebnis ein erhöhtes relatives Risiko von 1,4 für ICBs bei ASS-Einnahme statuierten (Garcia Rodriguez et al. 2016). Daher müssen Vor- und Nachteile einer präventiven ASS-Therapie stets sorgfältig abgewogen werden.

\subsubsection{Weitere Risikofaktoren}

Einen weiteren Risikofaktor stellt der Niktotinkonsum dar. Nach einer Studie von Abbot et al. (1986) haben Menschen mit regelmäßigem Niktotinkonsum ein zwei- bis dreifach erhöhtes Risiko, einen ischämischen oder hämorrhagischen Insult zu erleiden (Abbott et al. 1986). Weitere Risikofaktoren sind das Alter, das männliche Geschlecht (3,6-faches Risiko), ein schwerer Alkoholabusus (zweifaches Risiko), ein niedriger Cholesterinspiegel sowie der Abusus von Amphetaminen, Kokain (sechsfaches Risiko) oder Heroin (Ariesen et al. 2003; Qureshi et al. 2001a; Sturgeon et al. 2007).

Von genetischen Risikofaktoren für die Entstehung einer ICB wird ebenfalls ausgegangen, diese sind allerdings zur Zeit noch Gegenstand der Forschung (Rost et al. 2008). Beispielsweise wurde bei Patienten mit einer Punktmutation der DNA von Faktor XIII, welcher die Fibrinmoleküle miteinander verbindet, von einem erhöhten Risiko für Hirnblutungen berichtet (Catto et al. 1998).

\section{$1.4 \quad$ Einteilung der ICB}

Unterteilt wird die ICB in primäre und sekundäre Formen. Zwischen 78\% und 88\% der ICBs sind primärer Genese. Ursächlich hierfür ist die spontane Ruptur von kleinen 
Gefäßen, die durch einen chronischen Hypertonus bzw. Amyloidablagerungen pathologisch verändert sind (Qureshi et al. 2001b).

Sekundäre ICBs sind deutlich seltener und entstehen auf dem Boden einer nachgewiesenen Grunderkrankung, wie z. B. einer arteriovenösen Malformation (AVM), Aneurysmen, Tumore oder Gerinnungsstörungen (Qureshi et al. 2001b).

Zusätzlich werden ICBs je nach Lokalisation in lobär (die Großhirnlappen betreffend), tief liegend (Basalganglien, Thalamus, Hirnstamm betreffend) und zerebellär eingeteilt (Mutlu et al. 1963).

Die strenge Einteilung hinsichtlich Genese und Lokalisation ist überaus wichtig, da sich hiernach die individuelle Therapie richtet.

\subsection{Pathophysiologie der ICB}

\subsubsection{Primäre Hirnschädigung}

Es wird konstatiert, dass die Ursache einer primären, spontanen ICB ein pathologischer Gefäßumbau ist, der durch chronischen Bluthochdruck oder Amyloidablagerungen ausgelöst wird und von Fisher erstmalig als Lipohyalinose bezeichnet wurde (Fisher 1971). Die daraus resultierenden arteriosklerotischen Gefäße sind anfälliger für Gefäßverschlüsse und -rupturen. Kommt es zur Ruptur eines Gefäßes entsteht ein Hämatom, welches in der Folge eine neuronale Gewebeschädigung induziert, an welche sich ein dynamischer Prozess anschließt: Zunächst breitet sich das Blut innerhalb der weißen Substanz aus und umschließt Inseln von intaktem neuronalen Gewebe (Manno et al. 2005). Im Anschluss kommt es bei vielen Patienten in den ersten Stunden nach dem Blutungsereignis zu einer Hämatomexpansion (Broderick et al. 2007), korrelierend mit einer neurologischen Verschlechterung betroffener Patienten (Brott et al. 1997). In einer Studie von Davis et al. (2006) wurde eine generelle Zunahme des Blutvolumens bei 73\% der 218 untersuchten Patienten beobachtet mit einer assoziierten Auswirkung auf Mortalität und Prognose (Davis et al. 2006). 


\subsubsection{Sekundäre Hirnschädigung}

\subsubsection{Perihämorrhagisches Ödem}

$\mathrm{Zu}$ einer weiteren neurologischen Verschlechterung kommt es laut aktuellen Forschungsergebnissen durch die Entwicklung eines die Blutung umgebenden Ödems (perihematomal edema $=$ PHE), dessen Entstehung in drei Phasen aufgeteilt werden kann (Xi et al. 2006): In der ersten Phase (einige Stunden nach dem Blutungsereignis) wird über den erhöhten hydrostatischen Druck das Serum aus dem Blutgerinnsel in das umgebende Gewebe verschoben. In der zweiten Phase (einige Tage nach dem Blutungsereignis) wird die Gerinnungskaskade und die Thrombinproduktion aktiviert. In der dritten Phase folgt die Lyse der Erythrozyten und konsekutiv der Austritt von Hämoglobin, welches durch eisenabhängige Mechanismen neurotoxisch wirkt (Sadrzadeh et al. 1987). Abb. 1 liefert eine Übersicht über die Mechanismen, die zur Entwicklung des PHEs führen. 


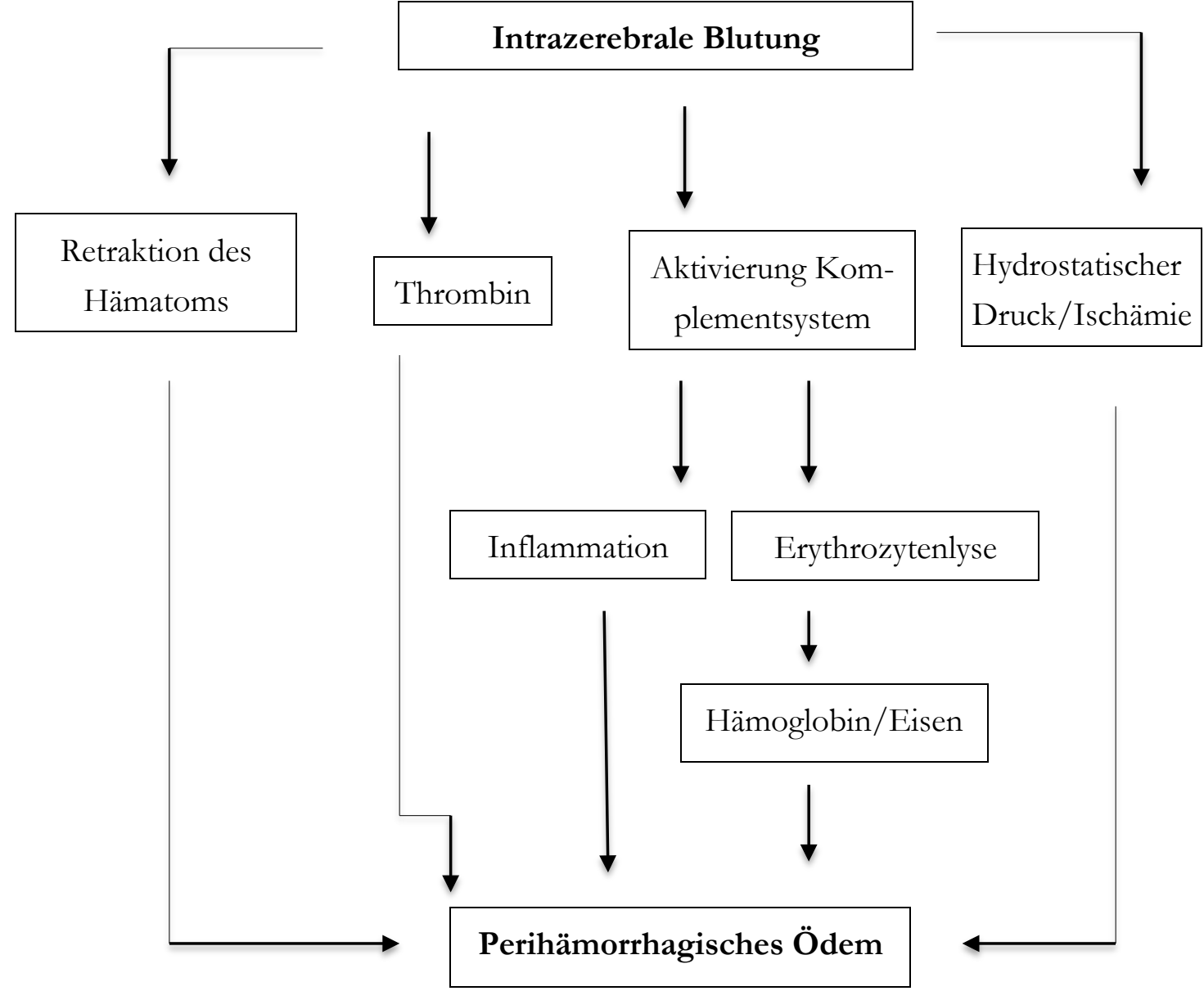

Abbildung 1: Schematische Darstellung der Mechanismen, welche zur Entwicklung eines PHEs führen (basierend auf Xi et al. 2006).

In einer Studie aus dem Jahr 2017 wurde die PHE-Expansionsrate nach 24 h (PHE24) sowie nach $72 \mathrm{~h}$ (PHE72) bei 115 Patienten berechnet. Die Größe des PHE24-Wertes und somit der frühen Ödembildung - korrelierte signifikant mit einer erhöhten 90Tages-Mortalität bei Patienten mit tiefen und lobären ICBs. Der PHE72-Wert war signifikant mit einem schlechten funktionellen Outcome bei Patienten mit tiefsitzender ICB assoziiert (Grunwald et al. 2017). 
Die Ergebnisse legen somit die Vermutung nahe, dass eine schnelle und effektive Volumenreduktion der ICB die PHE-Entwicklung reduziert und folglich mögliche blutungsassoziierte Schäden vermieden werden können.

\subsubsection{Penumbra}

Ein weiterer entscheidender Aspekt in Analogie zum ischämischen Schlaganfall ist die Frage nach der Entstehung einer Penumbra, einer potentiell reversibel geschädigten Randzone von Nervenzellen um das Infarktgebiet. Bisher wurde konstatiert, dass die Hämatomexpansion eine mikrovaskuläre mechanische Kompression bewirkt und sukzessive zum Zelluntergang führt (Brott et al. 1997). Ein wissenschaftlicher Beleg für diese Mutmaßung wurde bis dato nicht publiziert.

Mit Hilfe von perfusionsgewichteter CT-Bildgebung wurde anhand eines kleinen Patientenkollektivs ( $\mathrm{n}=5)$ eine Hypoperfusion in der perihämorrhagischen Randzone nachgewiesen (Rosand et al. 2002). In einer nachfolgenden prospektiven Studie (2003) wurden diffusions- und perfusionsgewichtete MRT-Aufnahmen bei 32 Patienten mit ICB durchgeführt. Zwar konnte bei einigen Patienten eine geringe Hypoperfusion innerhalb der Randzone diagnostiziert werden. Diese wurden jedoch nicht als zytotoxische Ischämie gewertet, sondern vielmehr als vasogene Ischämie und damit als Ausdruck eines reduzierten metabolischen Bedarfs der neuronalen Zellen, was als Diaschisis bezeichnet wird. Eine Korrelation der Hyperperfusion mit dem Patientenoutcome wurde nicht gefunden (Schellinger et al. 2003). Positronenemissionstomographische (PET) Untersuchungen, in denen die Penumbra bei 18 Patienten innerhalb von 22 Stunden nach Eintritt der ICB evaluiert wurde, konnten ebenso wenig Hinweise auf eine Ischämie innerhalb des perihämorrhagischen Areals liefern (Zazulia et al. 2001).

In einer 2007 veröffentlichten Studie wurden perfusionsgewichtete MRT-Bilder von 18 Patienten mit ICB erstellt und dabei der Fokus auf die Perfusion in der Penumbra gelegt. Die Autoren zogen drei wesentliche Schlussfolgerungen: Erstens war die perihämatomale Perfusion auch über die akute Phase hinaus beeinträchtigt. Zweitens variierte das Ausmaß der Hypoperfusion sowohl zwischen verschiedenen Hämatomen als auch zeitabhängig innerhalb desselben Hämatoms. Drittens könnte eine Subgruppe mit besonders stark ausgeprägter Minderperfusion (hier nicht näher definiert) von frühen spezifischen Behandlungsmaßnahmen profitieren (Pascual et al. 2007). 
Zusammenfassend ist die Genese der Penumbra einer ICB immer noch nicht abschlieBend geklärt und bleibt im Fokus weiterer Untersuchungen.

\subsubsection{Einbruch in das Ventrikelsystem und Hydrocephalus}

In 30-50\% der Fälle kommt es zu einem Einbruch der ICB in das Ventrikelsystem, was als intraventrikuläre Blutung (IVB) bezeichnet wird. Durch den lokalen Masseneffekt kann der Abfluss des Liquors verhindert werden, vor allem dann, wenn sich das Hämatom in den 3. oder 4. Ventrikel ausbreitet. Eine gefürchtete Komplikation ist hierbei die Ausbildung eines akuten obstruktiven Hydrocephalus. Bei diesen Patienten wird auf Grund der potentiellen Lebensbedrohung die unmittelbare Evakuation des Hämatoms dringend empfohlen (Balami und Buchan 2012). Neben dem obstruktiven Hydrocephalus kann sich als Spätfolge auch ein malresorptiver Hydrocephalus entwickeln, der durch die Verklebung der Arachnoidalzotten (Synonym: Pacchioni-Granulationen) durch die IVB entsteht. Hier ist die Anlage einer externen Ventrikeldrainage (EVD) indiziert (Huttner et al. 2007).

\subsection{Diagnostik der ICB}

Anhand von Anamnese und Klinik (Kopfschmerzen, Übelkeit, Erbrechen, neurologische Defizite bis hin zur Bewusstseinsstörung) ist die Unterscheidung zwischen ischämischen und hämorrhagischen Schlaganfall nicht zweifelsfrei möglich (Weir et al. 1994). Zur diagnostischen Verifizierung ist die Durchführung bildgebender Verfahren zwingend erforderlich. In der Regel wird zur Diagnostik einer akuten ICB eine native Computertomographie (CT) durchgeführt. Hierbei lassen sich genaue Angaben zu Lage und Größe des Hämatoms machen. Des Weiteren können intraventrikuläre, subarachnoidale oder subdurale Blutungen ausgeschlossen und die Gefahr eines Hydrozephalus oder einer Herniation eingeschätzt werden. Durch die hohe Sensitivität $(100 \%)$ bei der Detektion von akuten Blutungen und die schnelle und gute Verfügbarkeit ist das CT bei der primären Verdachtsdiagnose einer ICB bis heute der Goldstandard (Kidwell et al. 2004).

Genauso sensitiv hinsichtlich der Detektion akuter Hirnblutungen ist die Magnetresonanztomografie (MRT), allerdings erschweren Faktoren wie Kosten, Untersuchungs- 
dauer, Verfügbarkeit und Patiententoleranz den Einsatz (Singer et al. 2004). Signifikant überlegen ist die MRT bei der Erfassung chronischer Blutungen und mikroangiopathischer Schädigungen (Fan et al. 2004; Kidwell et al. 2004). Ist eine sekundäre Genese, z. B. durch eine vaskuläre Malformation, zu vermuten (z. B. bei einem jungen, normotensiven Patienten mit Lobärblutung), empfiehlt sich die zusätzliche Durchführung einer Magnetresonanzangiographie (MRA) oder CT-Angiographie (CTA). Durch Letztere können die Ursachen hinter den ICBs laut einer retrospektiven Studie von Romero et al. (2009) mit einer Sensitivität von 95\% und einer Spezifität von 100\% detektiert werden (Romero et al. 2009). Wird weder in der MRA noch in der CTA eine sekundäre vaskuläre Ursache gefunden und besteht gleichzeitig der dringende Verdacht auf eine vaskuläre Genese der ICB, ist die Durchführung einer digitalen Subtraktionsangiografie (DSA) indiziert. Kandidaten hierfür sind vor allem junge, normotensive Patienten, bei denen eine primäre Ursache sehr unwahrscheinlich ist (Qureshi et al. 2001b).

In der CTA lassen sich innerhalb des Hämatoms auch sogenannte spot signs identifizieren (siehe Abb. 2). Damit sind Bereiche von 1-2 mm Größe gemeint, in denen sich besonders viel Kontrastmittel anreichert und die somit in der CTA deutlich hervortreten. Wada et al. (2007) haben beschrieben, dass Patienten mit detektierten spot signs ein größeres Risiko für eine Expansion des Hämatoms und damit einer Akzentuierung des Krankheitsverlaufs haben (Wada et al. 2007).

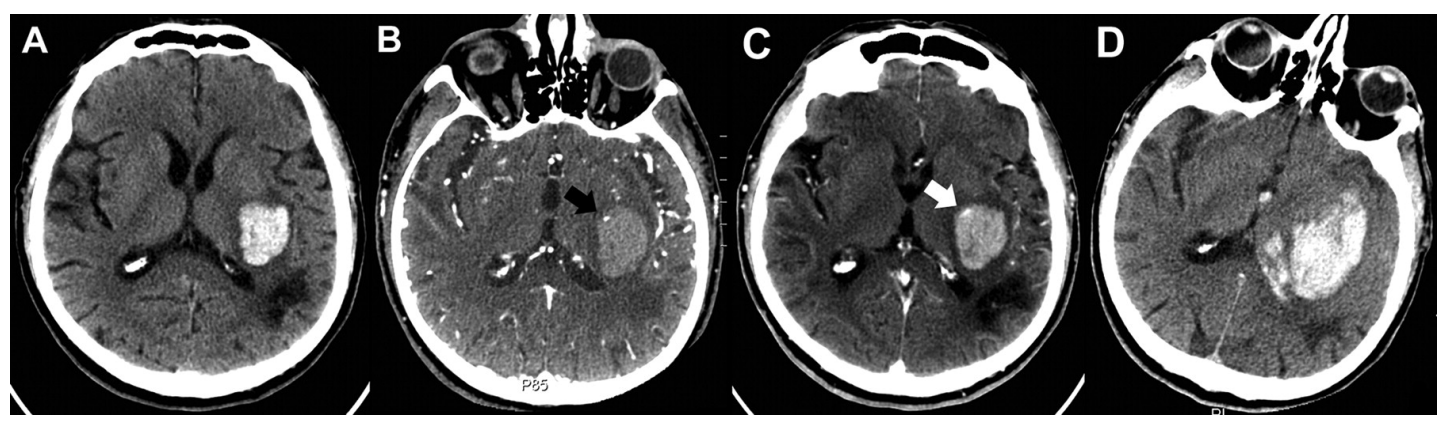

Abbildung 2: Bild A zeigt eine cCT-Aufnahme ohne Kontrastmittel. Die ICB ist in der Region von Putamen und Capsula interna lokalisiert und von einem PHE umgeben. Dorsal der ICB ist ein älterer abgelaufener Infarkt zu sehen. Bild B zeigt eine CTAAufnahme mit Kontrastmittel, der schwarze Pfeil markiert das spot sign. Auf Bild C, einem cCT-Bild unmittelbar nach Kontrastmittelgabe, markiert der weiße Pfeil das vergrößerte spot sign. Bild D zeigt die Hämatomexpansion einen Tag nach dem Blutungsereignis (Wada et al. 2007). 


\subsection{Therapie der ICB}

Die optimale Therapie von Patienten mit einer ICB bleibt ein komplexes Thema und befindet sich im ständigen Diskurs. Im Folgenden wird primär auf die initiale Versorgung, konservative sowie operative Maßnahmen eingegangen.

\subsubsection{Initiale Versorgung von Patienten mit einer ICB}

Die initiale Versorgung von Patienten mit einer ICB umfasst laut den Leitlinien der American Stroke Association (ASA) u. a. die Sicherstellung der Atemwege, das Monitoring der Vigilanz, die Einstellung einer adäquaten Gerinnung und eines normwertigen intrakraniellen Druckes (ICP = intracranial pressure) sowie die Überwachung und ggf. Normalisierung des Blutzuckers und der Körpertemperatur (Hemphill et al. 2015).

Gemäß den 2013 veröffentlichten Ergebnissen der ITERACT II-Studie (intensive blood pressure reduction in acute cerebral hemorrhage trial) empfiehlt die ASA derzeit eine intensive und schnelle Reduktion der systolischen Blutdruckwerte auf $<140 \mathrm{mmHg}$ bei Patienten mit einem systolischen Blutdruck zwischen 150 und $220 \mathrm{mmHg}$, sofern keine Kontraindikationen diesbezüglich vorliegen. Bei Patienten mit systolischen Werten von $>220 \mathrm{mmHg}$ soll die Blutdrucksenkung kontinuierlich intravenös unter Monitoring erfolgen (Hemphill et al. 2015). In der INTERACT-II-Studie wurden die Daten von 2794 Patienten mit einer ICB ausgewertet, von denen jeweils etwa die Hälfte eine intensive (Ziel-RR $<140 \mathrm{mmHg}$ ) bzw. leitliniengerechte (Ziel-RR $<180 \mathrm{mmHg}$ ) Behandlung erhielten. Die Studie zeigte keine signifikante Reduktion der Mortalität oder des primären Outcomes durch die intensivierte Blutdrucksenkung. Im Verlauf ließen sich jedoch positive Einflüsse der intensivierten Blutdrucksenkung auf das funktionelle Outcome mit Hilfe der modifizierten Rankin-Skala (mRS) ermitteln (Anderson et al. 2013). Diese Ergebnisse sowie die Sicherheit und Durchführbarkeit der Anwendung führten zur Revision der Leitlinie, sodass aktuell die intensivierte Blutdrucksenkung empfohlen wird (Hemphill et al. 2015).

Eine Empfehlung bezüglich des ICP-Managements bleibt auf Grund eines Mangels an Studien vage und orientiert sich lediglich an den Leitlinien für die Behandlung des Schädel-Hirn-Traumas. Ein Monitoring und ggf. die Senkung des ICPs (normal $<20 \mathrm{mmHg}$ ) wird hier u. a. bei Patienten mit einem Glasgow-Coma-Skala-Wert $<8$ oder bei einer in der cCT erkennbaren Herniation und IVBs empfohlen, da sich ein prognostisch günsti- 
ger Effekt der Hirndrucksenkung vermuten lässt (Carney et al. 2017). Drucksenkende Mittel sind sowohl Mannitol als auch hypertone Kochsalzlösung, wobei laut einer 2011 durchgeführten Metaanalyse letzteres effektiver zu sein scheint (Kamel et al. 2011).

\subsubsection{Hämatomevakuation über eine Kraniotomie}

Die Vorteile einer chirurgischen Intervention gegenüber einer alleinigen konservativen Therapie bei Patienten mit ICB werden seit längerem in der Literatur kontrovers diskutiert und sind bislang nicht eindeutig nachgewiesen worden.

Eine Behandlungsoption stellt die Hämatomevakuation über eine osteoplastische Kraniotomie dar. Durch die direkte Entfernung des Hämatoms soll eine Verminderung der sekundären Hirnschädigung bewirkt, der ICP reduziert und eine Herniation vermieden werden.

Dass sich dadurch eine Besserung der Patientenprognose ergibt, konnte bisher in diversen Studien nicht nachgewiesen werden (Hemphill et al. 2015). Zuletzt wurden angesichts dessen zwei große randomisierte und internationale Studien durchgeführt und deren Ergebnisse im Jahr 2005 (STICH-international surgical trial in intracerebral hemorrhage) und 2013 (STICH II) publiziert. Bei insgesamt 1634 Patienten mit einer ICB wurde die frühe chirurgische Intervention mit konservativen Therapieansätzen verglichen. Die Ergebnisse zeigten zum einen, dass durch einen frühen operativen Eingriff die Mortalität und Morbidität der Patienten nicht erhöht ist und sich demnach durch die Intervention keine Nachteile ergeben. Zudem wurde ein kleiner, klinisch relevanter Überlebensvorteil einer frühen chirurgischen Intervention bei gut zugänglichen, oberflächlichen, spontanen ICBs ohne begleitende IVB gemutmaßt. Letztendlich ergaben sich aber bezüglich der Patientenprognose keine signifikanten, verallgemeinerbaren Vorteile einer frühen chirurgischen Intervention gegenüber einem konservativen Behandlungsansatz. Bei komatösen Patienten (GCS $\leq 8)$ war das relative Risiko für ein schlechtes Outcome durch die frühe chirurgische Intervention um $8 \%$ erhöht; so scheint hier eine chirurgische Behandlung sogar schädlich zu sein (Mendelow et al. 2005; Mendelow et al. 2013). 


\subsubsection{Minimalinvasive Chirurgie (MIS), Lysekatheteranlage mit anschließender Fibrinolyse durch rtPA-Gabe}

Zusätzlich zu den chirurgischen Verfahren über eine Kraniotomie haben sich minimalinvasive Verfahren etabliert, durch welche eine sichere und schnelle Volumenreduktion des Hämatoms erreicht werden kann, um den Schaden des perihämorrhagischen Hirngewebes so gering wie möglich zu halten.

Zum einen gibt es die Möglichkeit das Hämatom endoskopisch zu evakuieren. 1989 wurden von Auer et al. Ergebnisse veröffentlicht, welche die Effektivität dieser Methode beschrieben haben. Bei Patienten mit subkortikalen ICBs wurde durch die endoskopische Operation ein besseres funktionelles Outcome im Vergleich zu der konservativ behandelten Gruppe erreicht (Auer et al. 1989). Aktuellere Daten beschreiben die endoskopische Evakuation über eine Bohrlochtrepanation oberhalb der Augenbraue als eine sichere und effiziente Technik bei anterioren Stammganglienblutungen (Dye et al. 2012). Eine neue, groß angelegte, multizentrische und randomisierte Studie hat das Ziel, endoskopische, stereotaktische und offen chirurgische Therapien bei hypertensiver supratentorieller ICB miteinander zu vergleichen und so die bestmögliche neurochirurgische Behandlung zu ermitteln (Xu et al. 2017).

Ein weiteres minimalinvasives Verfahren ist die CT-gestützte, navigierte Anlage eines Lysekatheters zur Hämatomdrainage zur Lysetherapie mittels rtPA-Applikation (recombinant tissue plasminogen activator). In der CLEAR-IVH-Studie (clot lysis: evaluating accelerated resolution of intraventricular hemorrhage) wurde die Wirksamkeit von rtPA-Gabe bei spontanen IVBs bei 64 Patienten getestet. Es wurden Placebo, 0,3 mg, $1 \mathrm{mg}$ oder $3 \mathrm{mg}$ rtPA nach Randomisierung über eine EVD appliziert. Die Ergebnisse zeigten, dass die rtPAGabe dosisabhängig die Auflösung des Hämatoms beschleunigt (Webb et al. 2012). In der weiterführenden Clear-III-Studie (2017) ist das funktionelle Outcome bei 500 Patienten mit IVB nach Anlage einer EVD und Applikation von rtPA bzw. Kochsalzlösung untersucht worden. Das funktionelle Outcome wurde mit Hilfe der mRS nach 180 Tagen ermittelt. Es konnte innerhalb der Stichprobe kein signifikanter Unterschied gefunden werden (Hanley et al. 2017).

Die größte bislang durchgeführte Studie in Bezug auf diese Technik ist die multizentrische, randomisierte MISTIE-Studie (minimally invasive surgery plus rt-P A for ICH evacuation). Die Zwischenergebnisse der Phase-2-Studie (MISTIE II, 2008) legten bereits nahe, dass es sich um ein sicheres Verfahren handelt und im Vergleich zur konservativen Behand- 
lung zur effektiveren und schnelleren Hämatomlyse führt. Des Weiteren wurde von den Autoren gemutmaßt, dass die Effektivität der Lysetherapie einerseits von der Lage des Katheters und andererseits von der Lokalisation der Blutung abhängt (Morgan et al. 2008a; Morgan et al. 2008b).

Die von Mould et al. (2013) dargestellten Interpretationen bestätigen die sichere Anwendung des Verfahrens. Zudem konnte eine signifikante Reduktion des PHEs beobachtet und eine neurotoxische Wirkung der intrahämatomalen rtPA-Applikation weitestgehend ausgeschlossen werden (Mould et al. 2013). Hanley et al. (2016) warnten indes vor asymptomatischen Nachblutungen als mögliche Nebenwirkung der Therapie (Hanley et al. 2016).

Aktuell liegen die Daten der MISTIE-III-Studie (2019) vor, in welche 499 Patienten aus insgesamt 78 Zentren eingeschlossen werden konnten. Einer operativen Behandlung wurden 250 (50\%) Patienten zugeführt und 249 (50\%) wurden für die bestmögliche konservative Therapie randomisiert. Bezogen auf das Patientenoutcome ließen sich keine signifikanten Unterschiede beider Methoden nach einem Follow-up von 365 Tagen eruieren (Hanley et al. 2019). Die 180-Tages-Mortalität der Patienten in der MISTIE-Gruppe war insgesamt etwas geringer (15\% MISTIE vs. 23\% best medical treatment innerhalb der ersten 180 Tage, p=0,033). Eine signifikant erhöhte Komplikationsrate in der operativen Gruppe durch Infektionen oder symptomatischen Blutungen wurde nicht ermittelt (Hanley et al. 2019).

Des Weiteren wird zur Zeit in England die MISTICH-Studie (minimally invasive surgery treatment for the patients with spontaneous supratentorial intracerebral hemorrbage) durchgeführt, eine multizentrische randomisierte Studie, die untersucht, ob minimalinvasive Eingriffe bei spontaner ICB mit einer besseren Prognose einhergehen als Eingriffe mittels Kraniotomie (Zheng et al. 2014).

Zeitgleich findet die Rekrutierung von Patienten für die SWITCH-Studie (swiss trial of decompressive craniectomy versus best medical treatment of spontaneous supratentorial intracerebral hemorrbage) statt. Bisher konnten knapp 100 Patienten eingeschlossen werden. Verglichen wird die operative Behandlung einer ICB über eine dekompressive Hemikraniektomie mit der konservativen Behandlung bei tiefliegenden ICBs (SWITCH-Studie). 


\subsection{Zielsetzung}

Während die optimale Versorgung einer ICB weiterhin Gegenstand kontroverser Debatten ist, stellt die MIS mit rtPA-Lyse derzeit einen vielversprechenden Therapieversuch dar, der in einzelnen Kliniken zur Volumenreduktion bei ICB angewendet wird. Zur effektiven Fibrinolyse wurde bislang angenommen, dass eine zentrale Position des Katheters entlang des größten Hämatomdurchmessers besonders effektiv ist (Rohde et al. 2000; Thiex et al. 2004).

Ziel der vorliegenden Arbeit ist zu evaluieren, ob die Lage des Lysekatheters einen signifikanten Einfluss auf die Effektivität der Hämatomlyse hat und ob die Katheterlage mit dem Patientenoutcome korreliert.

Des Weiteren sollen anhand der chronologischen bildmorphologischen Darstellung der Hämatomlyse und dem Muster der Hämatomreduktion in Abhängigkeit von der Katheterlage Informationen über die Verteilung von rtPA innerhalb des Hämatoms gewonnen werden. 


\section{$2 \quad$ Patienten und Methoden}

\subsection{Studiendesign und Patientenkollektiv}

In diese Studie konnten 105 Patienten retrospektiv eingeschlossen werden, die zwischen Januar 2010 und August 2015 eine spontane ICB erlitten und nach einer CT-gestützten Katheteranlage mittels rtPA fibrinolytisch in der neurochirurgischen Abteilung des Uniklinikums Göttingen behandelt wurden. Zur Erstellung einer Datenbank wurden die im Computersystem des Klinikums archivierten CT-Aufnahmen und Patientendaten verwendet.

Die Diagnose der ICB wurde via cCT ohne Kontrastmittel gestellt. Bei Lobärblutungen jüngerer Patienten (<65 Jahre) ohne Hypertension oder Antikoagulation in der Vorgeschichte wurde eine Gefäßmalformation oder eine andere sekundäre Genese der ICB mittels CTA ausgeschlossen. Die Behandlung wurde innerhalb von 24 Stunden nach Symptombeginn initiiert.

Zur allgemeinen Eignung für eine fibrinolytische Therapie mussten die Patienten die folgenden Voraussetzungen erfüllen: Das Hämatomvolumen musste zwischen $30 \mathrm{ml}$ und $150 \mathrm{ml}$ liegen und der GCS zwischen 6 und 12 Punkten vor der Intubation betragen (unter Ausschluss der tief komatösen Patienten).

Nicht geeignet waren Patienten mit einem GCS zwischen 13 und 15 oder jene mit einer bereits eingetretenen zerebralen Herniation oder fataler Prognose. Ebenfalls nicht geeignet waren Patienten mit ICBs, die durch einen eingebluteten Infarkt oder durch eine sekundäre Genese entstanden waren.

Die finale Entscheidung für oder gegen eine chirurgische Intervention und, bei Lobärhämatomen, für eine fibrinolytische Therapie oder eine mikrochirurgische Hämatomevakuation unterlag dem Urteil des verantwortlichen Neurochirurgen.

Bei Lobärblutungen wurde bei jüngeren Patienten ohne Komorbiditäten tendenziell öfter mikrochirurgisch interveniert. 


\subsubsection{Datenerhebung und chirurgisches Verfahren}

Für die Katheteranlage wurden sowohl die rahmenlose Stereotaxie mit Gelenkarm und Hülse sowie die rahmenlose Stereotaxie mittels navigiertem Stylet durchgeführt. Die Verfahren wurden in einer Studie von Malinova et al. (2014) bereits beschrieben, wobei die neue Stylet-Technik eine signifikant höhere Genauigkeit der Lysekatheteranlage gezeigt hatte. Der Vollständigkeit halber sollen im Folgenden beide Verfahren kurz erläutert werden.

\subsubsection{Rahmenlose Stereotaxie mit Gelenkarm und Hülse oder navigiertem Stylet}

Zur Planung der Operation wird bei allen Patienten eine Serie von CT-Aufnahmen angefertigt, um einen Navigationsdatensatz zu erhalten. Zu Beginn der Operation erfolgt die Fixierung des Kopfes des Patienten in einer Mayfield-Klemme. Bei Anwendung der rahmenlosen Stereotaxie mit Gelenkarm und Hülse wird mit Hilfe der virtuellen Pointer-Verlängerung und Neuronavigation der Eintrittspunkt und die Trajektorie entlang des größten Durchmessers des Hämatoms intraoperativ geplant. Auch die Länge und Penetrationstiefe des Katheters wird auf diese Weise ermittelt. Bei Verwendung des navigierten Stylets fungiert dieser als Navigationspointer und wird zur Planung des Eintrittspunktes und der optimalen Katheterlage genutzt.

Anschließend erfolgt die Inzision und eine 4-mm-Bohrloch-Trepanation am errechneten Eintrittspunkt. Dann wird der Katheter entweder mit einer Hülse über einen Gelenkarm oder mit Hilfe des navigierten Stylets eingeführt (siehe Abb. 3 und 4). Bei beiden Techniken wird ein Silikonkatheter mit einem Durchmesser von $3 \mathrm{~mm}$ und mit Öffnungen entlang der oberen $3 \mathrm{~cm}$ des Katheters verwendet. Die Fixierung des Katheters erfolgt, sobald sich das Hämatom entleert oder aspiriert werden kann und somit dessen intrahämatomale Lage verifiziert werden konnte. 


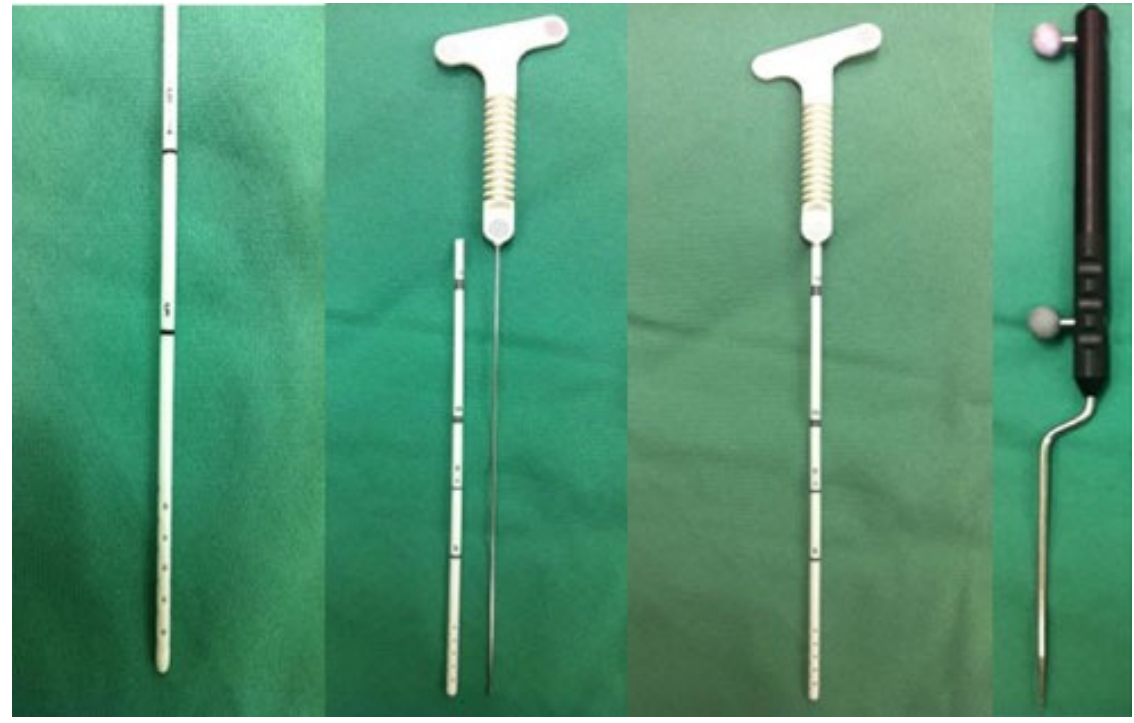

Abbildung 3: Die linken drei Abbildungen zeigen die Katheter mit der Hülse, rechts ist der navigierte Stylet dargestellt.

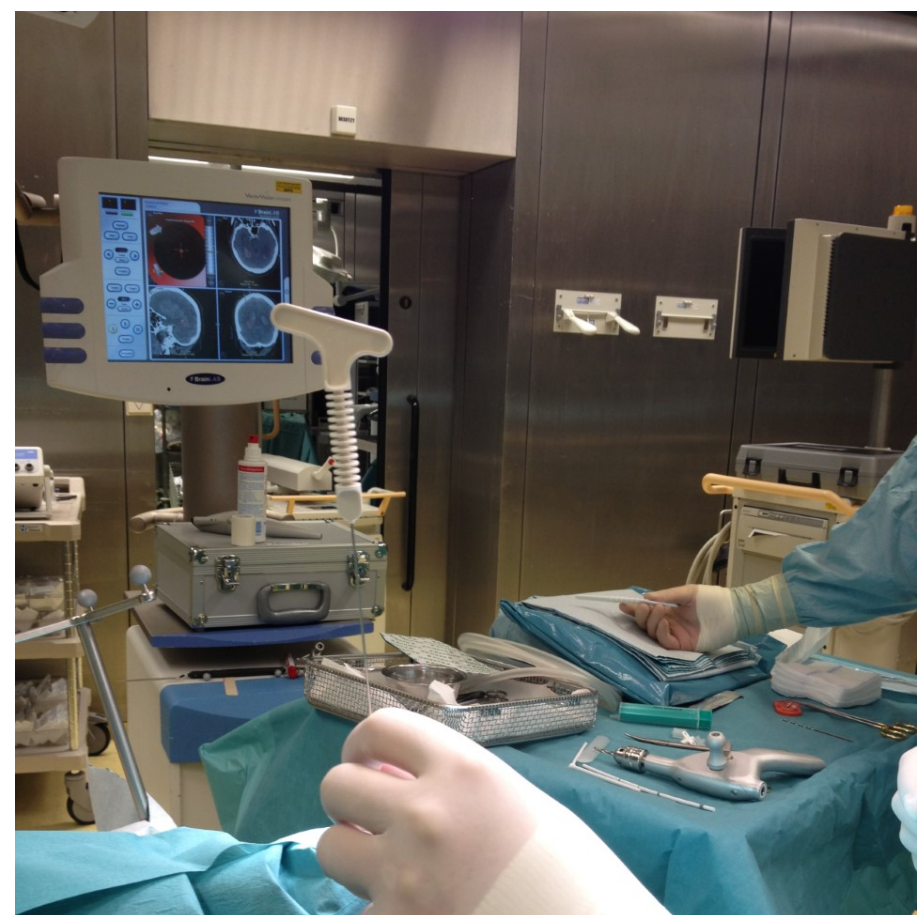

Abbildung 4: Operatives Setting mit Einführung des Lysekatheters über die Hülse und intraoperativer Navigation. 
Postoperativ wird ein Kontroll-cCT angefertigt, um die intrahämatomale Lage des Lysekatheters zu bestätigen. Bei nachgewiesener intrahämatomaler Katheterlage erfolgt die Injektion von $5 \mathrm{mg}$ rtPA (Actilyse ${ }^{\circledR}$ Boehringer Ingelheim Pharma GmbH \& Co, KG Ingelheim am Rhein, Germany) und das Abklemmen des Katheters für 30 min, um eine adäquate Wirkdauer des Fibrinolytikums zu gewährleisten. Anschließend erfolgt die Drainage des lysierten Gerinnsels gegen einen negativen Druck für 24 Stunden, gemäß etabliertem Protokoll (Schaller et al. 1995; Teernstra et al. 2003; Thiex et al. 2004). Die Injektion von $5 \mathrm{mg}$ rtPA wird zweifach wiederholt, jeweils nach 24 Stunden und nach CT-gestützter Verifizierung einer weiterhin intrahämatomalen Lage des Katheters. Wird eine durch die Hämatomlyse verursachte intraparenchymale statt intrahämatomale Lage der Katheteröffnung (obere $3 \mathrm{~cm}$ ) festgestellt, so wird der Katheter entfernt. In Abb. 5 und Abb. 6 werden zur Veranschaulichung CT-Aufnahmen der postoperativen Hämatome mit jeweils zentraler und randständiger Katheterlage gezeigt.

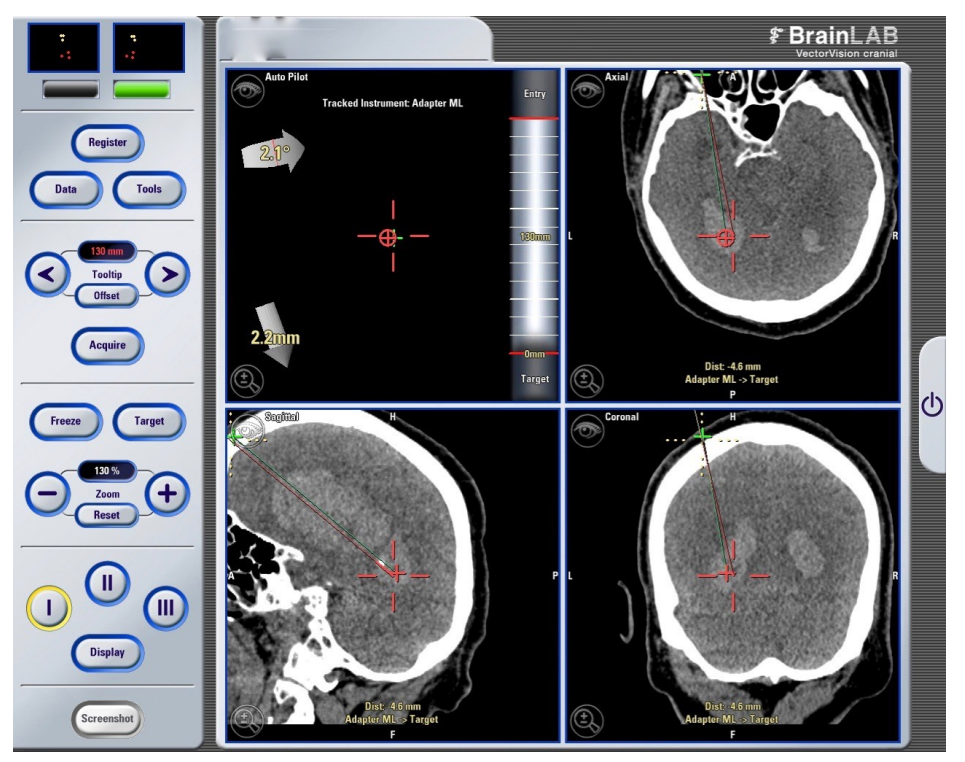

Abbildung 5: Postoperative CT-Aufnahme. Hier befindet sich der Lysekatheter (rot markiert) in zentraler Lage. 


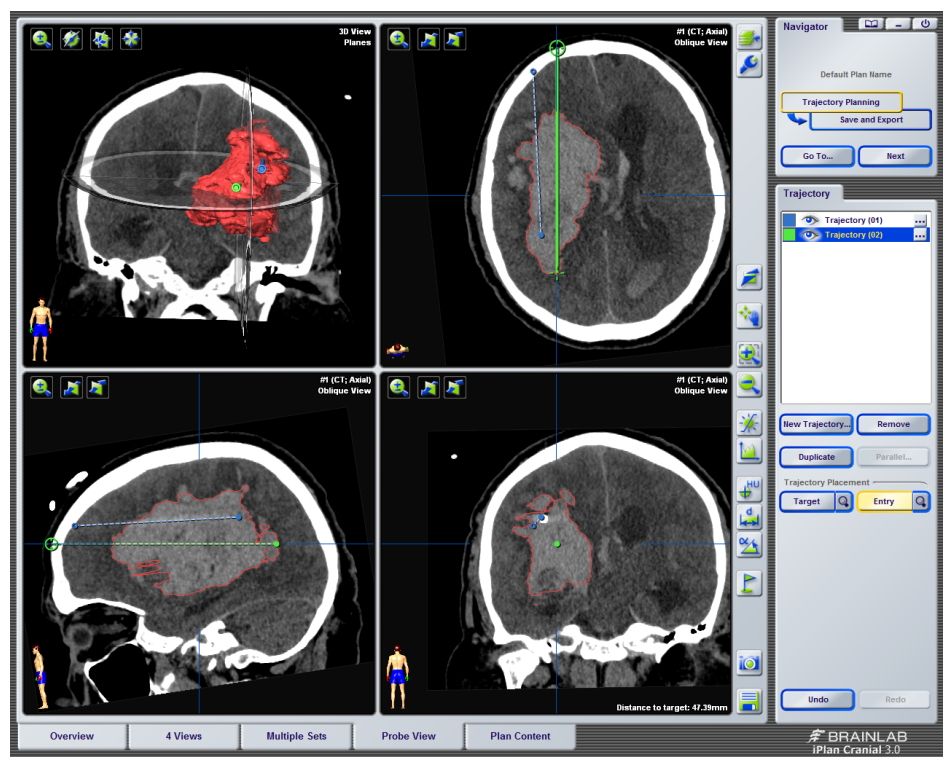

Abbildung 6: Postoperative CT-Aufnahme. Zu sehen ist der Lysekatheter in randständiger Lage (blau). Zum Vergleich ist die optimale zentrale Katheterlage eingezeichnet (grün).

\subsubsection{Postoperatives Vorgehen}

Eine routinemäßige ICP-Messung wurde nicht durchgeführt. Im Gegensatz zur MISTIE-Studie wurde kein zweites CT zur Sicherstellung der Hämatomstabilität durchgeführt. Die Prognose der Patienten bei Entlassung wurde mittels GOS bewertet (siehe unten).

\subsubsection{Erfasste Patientendaten}

Wir sammelten demographische Daten der Patienten, wie Geschlecht und Alter sowie das Datum der Operation und die angewandte Technik (navigierter Stylet vs. rahmenlose Stereotaxie mit Gelenkarm und Hülse). Außerdem erfolgte die Datenerhebung hinsichtlich der Lage (lobär und tief) und des Volumens der Hämatome jeweils vor und nach der Operation und nach jeder Lysegabe anhand der durchgeführten cCTs. Ebenfalls erfasst wurden neu aufgetretene Komplikationen, wie eine Ausweitung der Blutung in das Ventrikelsystem, Infektionen, parenchymatöse Nachblutungen, die Ausbildung eines Hydrocephalus bis hin zum Tod der Patienten. Die erfassten Daten sind in Tabelle 1 zusammengestellt. 
Tabelle 1: Zusammenfassung der klinischen Patientendaten

\section{Charakteristika}

Mittleres Alter

Geschlecht (w/m)

Lage des Hämatoms (tief/lobär)

Mittleres Hämatomvolumen nach Katheteranlage (ml)

Mittlerer RE

Mittlere RVR

Intraventrikuläre Ausbreitung

Infektion

Hydrocephalus

Mittlerer GOS-Wert

Mortalität während des Krankenhausaufenthalts

\subsection{Quantitative Analyse der Daten}

\subsubsection{Katheterposition und relative error (RE)}

Die Katheterposition in dem Hämatom wurde mit Hilfe eines vordefinierten, von unserer Arbeitsgruppe publiziertem relative error (RE) berechnet (Malinova et al. 2014). Die RE-Werte beschreiben die Abweichung der real gemessenen Lage des Katheters in Relation zur idealen zentralen Lage entlang des größten Hämatomdurchmessers. Ihre Auswertung erfolgte auf den direkt postoperativ durchgeführten cCT-Aufnahmen. Hierzu wurden die Abstände des Katheterzentrums zu allen vier Rändern des Hämatoms perpendikular und manuell gemessen und mit A, B, C und D gekennzeichnet. Beispielhaft ist dies in Abb. 7 dargestellt. 


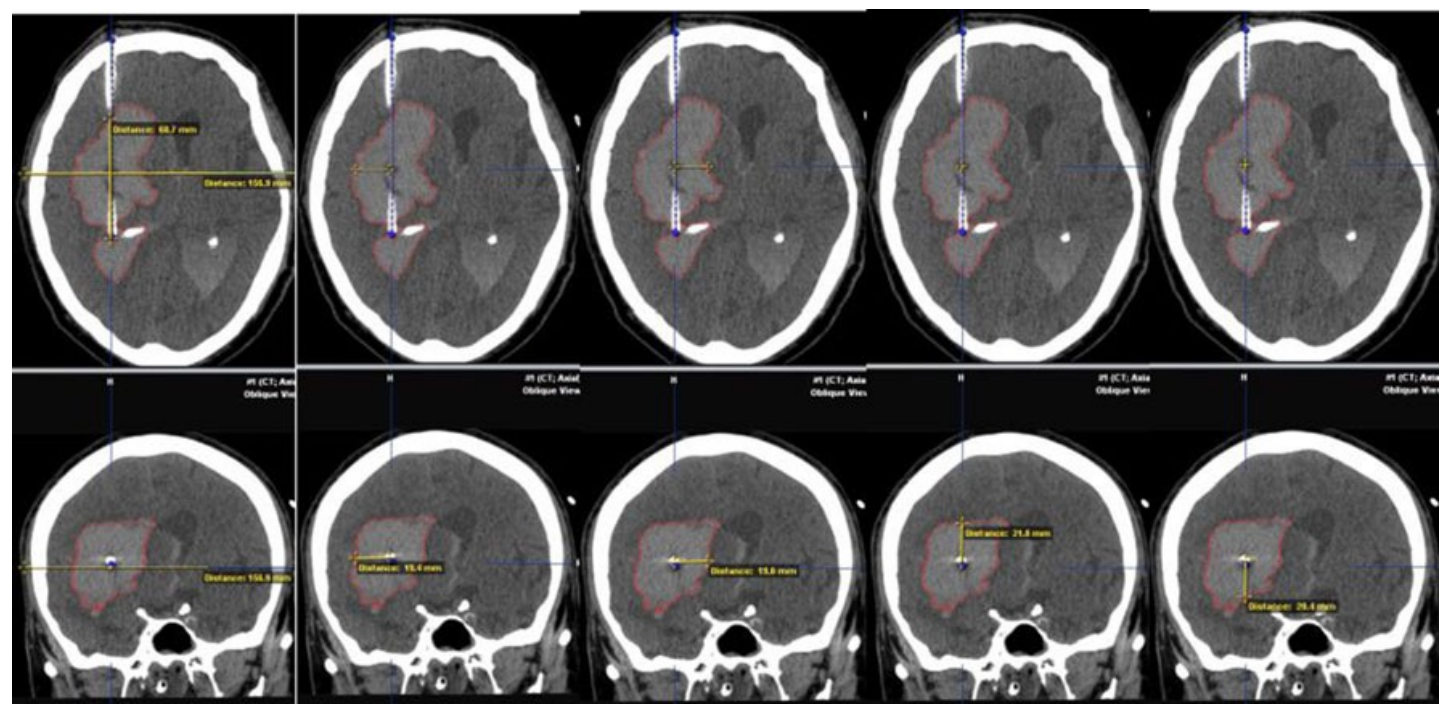

Abbildung 7: Exemplarisch eine Reihe von postoperativen CT-Bildern einer ICB nach Katheteranlage und Bearbeitung mit der BrainLab ${ }^{\mathbb{O}}$-Software.

Daraufhin wurde der RE mit Hilfe folgender Gleichung berechnet:

$\mathrm{RE}=(|\mathrm{A}-\mathrm{B}| /(\mathrm{A}+\mathrm{B})+|\mathrm{C}-\mathrm{D}| /(\mathrm{C}+\mathrm{D}))$

Der Bereich des REs liegt zwischen 0 und 2, wobei ein RE von 0 die ideale Katheterposition entlang des größten Hämatomdiameters und ein RE von 2 eine Position außerhalb des Hämatoms beschreibt. Ein RE zwischen 0 und 1 zeigt eine Katheterlage fast parallel zum größten Durchmesser mit leichtgradiger Abweichung vom Zentrum. Ein RE zwischen 1 und 2 beschreibt eine randständige, aber intrahämatomale Katheterlage. Die anschauliche Darstellung zeigt Abb. 8. 


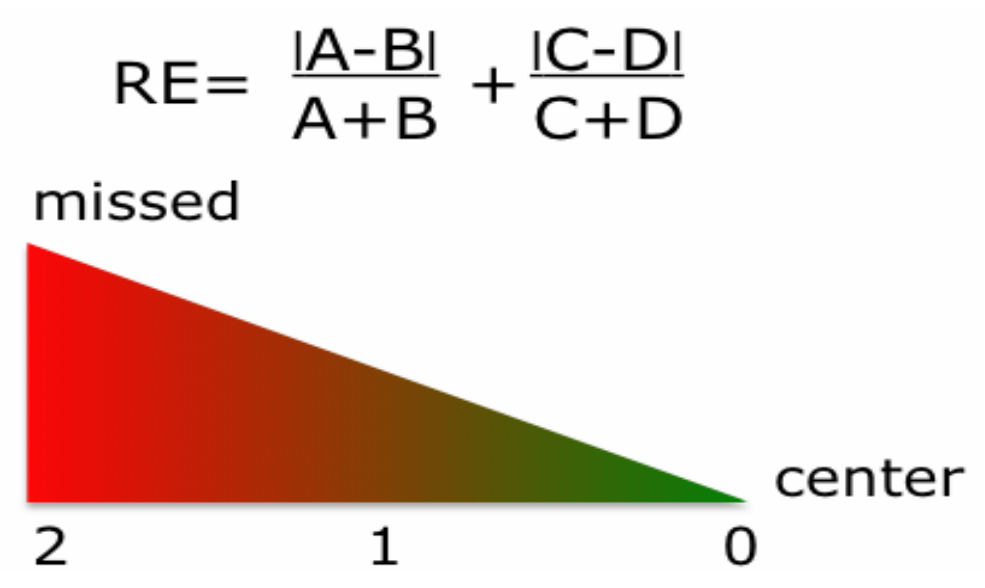

Abbildung 8: Berechnung und Bereich des RE (Malinova et al. 2017), mit Genehmigung von Frau Dr. V. Malinova.

\subsubsection{Relative Volumenreduktion (RVR)}

Das Hämatomvolumen wurde anhand der cCT-Aufnahmen vor Katheteranlage, direkt nach Katheteranlage, nach jeder rtPA-Injektion und schlussendlich nach Entfernung des Katheters mit Hilfe der BrainLab ${ }^{\circledR}$-Software (iPlan 3.0 BrainLab ${ }^{\circledR}$, Feldkirchen, Germany) berechnet. Anschließend wurde mit Hilfe der angefertigten cCT-Aufnahmen und selbiger Software das Hämatomvolumen nach 24, 48 und 72 h ermittelt. So konnte die relative Volumenreduktion (RVR) errechnet werden.

Da wir uns auf die rtPA-induzierte Hämatomvolumenreduktion fokussiert haben, wurde die RVR nach dem letzten Tag der Lysebehandlung gemessen, um Effekte der physiologischen Hämatomresorption auszuschließen.

Evaluiert wurde zum einen der Zusammenhang zwischen dem RE und der RVR. Zum anderen wurde der Effekt der Katheterlage auf den neurologischen Zustand der Patienten zum Zeitpunkt der Entlassung (GOS) analysiert. 


\subsection{Qualitative Analyse}

Ein 3D-Modell des Hämatoms inklusive des platzierten Katheters wurde jeweils nach der Operation, vor der ersten rtPA-Injektion sowie nach jeder folgenden rtPA-Injektion und abschließend nach der Katheterentfernung mittels der BrainLab ${ }^{\circ}$-Software angefertigt. Die 3D-Modelle der einzelnen Patienten wurden extrahiert und mit Hilfe der Transparenzfunktion von PowerPoint ${ }^{\circ}$ (Microsoft Office Software Version 2010) zusammengefügt. Dies erlaubt eine qualitative Analyse der zeitlichen Volumenreduktion in Relation zur Katheterposition.

\subsection{Statistische Analyse}

Die statistische Analyse wurde mittels der GraphPad-Prism-Software (GraphPadSoftware, La Jolla, USA) durchgeführt. Für die Berechnung des RVR wurden deskriptive Statistikmethoden verwendet. Die Korrelation zwischen RVR und intrahämatomaler Katheterposition und die Korrelation zwischen der Katheterposition und dem Patientenoutcome wurden untersucht. Ein p-Wert $<0,05$ wurde als statistisch signifikant erachtet. 


\subsection{Die Glasgow-Coma-Skala (GCS)}

Die GCS wurde initial entwickelt, um insbesondere den Bewusstseinsgrad und klinischen Zustand von Patienten nach Schädel-Hirn-Traumen beurteilen zu können (Teasdale und Jennett 1974). Hierfür werden drei Kategorien verwendet, welche entsprechend der Ausprägung und in Abhängigkeit von der Kategorie mit 1 bis 6 Punkten bewertet werden: Augenöffnen (1-4 Punkte), verbale Kommunikation (1-5 Punkte) und motorische Reaktion (1-6 Punkte), siehe hierzu Tabelle 2. Wir verwendeten die Skala zur initialen Bewusstseinseinschätzung und Therapieplanung.

Tabelle 2: Glasgow-Coma-Skala (basierend auf Teasdale und Jennett 1974)

\begin{tabular}{|l|l|c|}
\hline \multirow{5}{*}{ Augenöffnen } & Spontan & 4 \\
\cline { 2 - 3 } & Auf Aufforderung & 3 \\
\cline { 2 - 3 } & Auf Schmerzreiz & 2 \\
\cline { 2 - 3 } & Keine Reaktion & 1 \\
\hline \multirow{5}{*}{ Verbale Kommunikation } & Konversationsfähig, orientiert & 5 \\
\cline { 2 - 3 } & Konversationsfähig, desorientiert & 4 \\
\cline { 2 - 3 } & Unzusammenhängende Wörter & 3 \\
\cline { 2 - 3 } & Unverständliche Laute & 2 \\
\cline { 2 - 3 } & Keine verbale Reaktion & 1 \\
\hline \multirow{5}{*}{ Motorische Reaktion } & Befolgen von Aufforderungen & 6 \\
\cline { 2 - 3 } & Gezielte Abwehr auf Schmerzreiz & 5 \\
\cline { 2 - 3 } & Zurückziehen auf Schmerzreiz & 4 \\
\cline { 2 - 3 } & Beugesynergismen auf Schmerzreiz & 3 \\
\cline { 2 - 3 } & Strecksynergismen auf Schmerzreiz & 2 \\
\cline { 2 - 3 } & Keine motorische Reaktion & 1 \\
\hline
\end{tabular}




\subsection{Die Glasgow-Outcome-Skala (GOS)}

Die GOS wurde 1975 von Jennett und Bond publiziert (Jennett und Bond 1975; McMillan et al. 2016). Sie wurde verfasst, um den physischen sowie mentalen Erholungszustand eines Patienten nach einer Gehirnverletzung bei Krankenhausentlassung möglichst objektiv dokumentieren zu können. Die GOS definiert fünf Stadien, ausgehend von geringer über mäßige und schwere Behinderung, bis hin zum persistierenden vegetativen Zustand und dem Tod des Patienten. Bis heute ist sie im Krankenhausalltag sowie im Rahmen klinischer Studien dank ihrer Validität, Flexibilität und Reliabilität eine gängige Bewertungsmethode bei Patienten nach Gehirnverletzungen (McMillan et al. 2016).

Wir dokumentierten die GOS bei Entlassung unserer Patienten und nahmen für die Auswertung unserer Ergebnisse eine Dichotomisierung in gut (GOS 3-5) und schlecht (GOS 1-2) vor.

Tabelle 3: Glasgow-Outcome-Skala (basierend auf Jennett und Bond 1975)

\begin{tabular}{|l|l|}
\hline GOS 1 & Versterben in Folge der akuten Hirnschädigung \\
\hline GOS 2 & Apallisch, bleibender vegetativer Zustand \\
\hline GOS 3 & $\begin{array}{l}\text { Schwerbehindert (geistig und/oder körperlich, auf dauernde Versor- } \\
\text { gung angewiesen, keine Erwerbsfähigkeit) }\end{array}$ \\
\hline GOS 4 & $\begin{array}{l}\text { Mittelgradig behindert, weitestgehend selbständig, aber deutliche } \\
\text { neurologische und/oder psychische Störungen, erhebliche Ein- } \\
\text { schränkungen der Erwerbsfähigkeit }\end{array}$ \\
\hline GOS 5 & $\begin{array}{l}\text { Nicht/leicht behindert, normale Lebensführung trotz eventuell } \\
\text { geringer Ausfälle, nur geringe Einschränkung der Erwerbsfähigkeit }\end{array}$ \\
\hline
\end{tabular}




\section{Ergebnisse}

Insgesamt wurden 105 Patienten mit spontaner ICB und durchgeführter Lysetherapie retrospektiv analysiert. Das mittlere Alter der Patienten betrug 67,6 Jahre (30-92 Jahre), wobei es sich um 61 Männer und 44 Frauen handelte. Tiefsitzend waren 59 (56\%) der Hämatome, während 46 (44\%) der Hämatome eine lobäre Lage aufwiesen. Die Anlage des Lysekatheters erfolgte bei 52 Patienten (49\%) mittels rahmenloser Stereotaxie mit Gelenkarm und Hülse und bei 53 Patienten (51\%) mit dem navigierten Stylet. Das mittlere Hämatomvolumen nach Katheterimplantation und vor der ersten Lysegabe betrug $56 \mathrm{ml}$ (30-143 ml). Der mittlere RE lag bei 0,6, die mittlere RVR bei 62,7\% und der mittlere GOS-Wert bei 2,4.

\subsection{Komplikationen}

Bei 84 Patienten wurde eine intraventrikuläre Ausbreitung des Hämatoms und bei 21 Patienten ein Hydrocephalus detektiert. Die Infektionsrate betrug 14\%, wobei hier mitunter die Lysekatheter mit Anschluss an das Ventrikelsystem ursächlich gewesen sein könnten, die postoperativ als EVD genutzt wurden und somit das Infektionsrisiko steigerten. Eine Korrelation zwischen Katheterlage und Infektionsrate konnte derweil nicht nachgewiesen werden. Ebenso wenig festgestellt haben wir einen Zusammenhang zwischen randständiger Katheterlage und Nachblutungen bzw. neu aufgetretenen neurologischen Defiziten. Von den 105 Patienten verstarben 34 (32\%) im Verlauf.

Die Daten sind in Tab. 4 nochmals zusammengefasst. 
Tabelle 4: Zusammenfassung der Patientencharakteristika und Ergebnisse

\begin{tabular}{|c|c|}
\hline \multicolumn{2}{|l|}{ Charakteristika } \\
\hline Mittleres Alter (Jahre) & 67,6 \\
\hline \multicolumn{2}{|l|}{ Geschlecht } \\
\hline Weiblich & $44(42 \%)$ \\
\hline Männlich & $61(58 \%)$ \\
\hline \multicolumn{2}{|l|}{ Technik } \\
\hline Rahmenlos mit Gelenkarm und Hülse & $52(49 \%)$ \\
\hline Navigierter Stylet & $53(51 \%)$ \\
\hline Mittleres Hämatomvolumen nach Katheteranlage (ml) & 56 \\
\hline \multicolumn{2}{|l|}{ Lage des Hämatoms } \\
\hline Tief & $59(56 \%)$ \\
\hline Lobär & $46(44 \%)$ \\
\hline Intraventrikuläre Ausbreitung & $84(80 \%)$ \\
\hline Mittlerer RE & 0,64 \\
\hline Mittlere RVR & $62,7 \%$ \\
\hline Mittlerer GOS-Wert & 2,4 \\
\hline Hydrozephalus & $22(21 \%)$ \\
\hline Infektion & $15(14 \%)$ \\
\hline Verstorben & $34(32 \%)$ \\
\hline
\end{tabular}




\subsection{Ergebnisse der quantitativen Analyse}

Die mittlere RVR nach 24 h betrug im Schnitt 31,7\%, nach 48 h 45,6\% und nach 72 h $55,2 \%$. Die gesamte RVR betrug 62,7\%. Eine ideale zentrale Katheterposition entlang des größten Hämatomdurchmessers bzw. eine Position mit minimaler Abweichung (RE 0,0-0,7) wurde bei 69 Patienten (65,7\%) erreicht. Eine Katheterposition mit größerer Abweichung (RE 0,7-1,4) fand sich bei $32(30,5 \%)$ Patienten und eine randständige Katheterlage wiesen vier (3,8\%) Patienten auf. Das mittlere initiale Hämatomvolumen der Patienten mit einem RE von 0,0-0,7 betrug 57,8 ml, die Patienten mit einem RE von 0,7-1,4 wiesen ein mittleres Volumen von 51,0 $\mathrm{ml}$ auf und die Patienten mit einem RE von 1,4-1,9 eines von 61,4 ml. Die RVR des Hämatoms nach $72 \mathrm{~h}$ war in der Gruppe RE 0,0-0,7 50,2\%, in der Gruppe RE 0,7-1,4 betrug sie 54,1\% und in der Gruppe RE 1,4-1,9 waren es 97,8\%. Eine Zusammenfassung der Daten ist in Tab. 5 nochmals aufgeführt.

Tabelle 5: Darstellung des Zusammenhangs zwischen RE und Hämatomvolumina

\begin{tabular}{|l|l|l|l|}
\hline RE & $0,0-0,7$ & $0,7-1,4$ & $1,4-1,9$ \\
\hline Patientenanzahl & $69(65,7 \%)$ & $32(30,5 \%)$ & $4(3,8 \%)$ \\
\hline $\begin{array}{l}\text { Mittleres initiales } \\
\text { Hämatomvolumen }\end{array}$ & $57,8 \mathrm{ml}$ & $51,0 \mathrm{ml}$ & $61,4 \mathrm{ml}$ \\
\hline RVR nach 72 h & $50,2 \%$ & $54,1 \%$ & $97,7 \%$ \\
\hline
\end{tabular}

Es konnte keine signifikante Korrelation zwischen der Katheterlage und der Hämatomvolumenreduktion nachgewiesen werden (lineare Abnahme, $\mathrm{p}=0,14)$ (Abb. 9). 
Lineare Abnahme

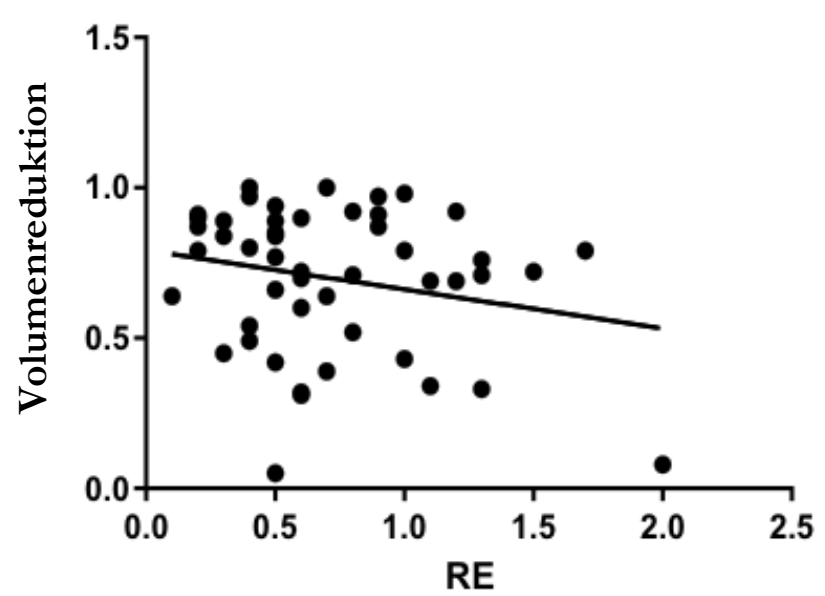

Abbildung 9: Korrelation zwischen RVR und RE (Malinova et al. 2017), mit Genehmigung von Frau Dr. V. Malinova.

Eine gute Prognose (GOS 3-5) wiesen 66\% (69/105) aller Patienten auf, wobei dies bei 63\% (43/69) der Patienten mit zentraler Katheterlage und 62\% (22/36) der Patienten mit weniger optimaler Katheterlage der Fall war. Das mittlere initiale Hämatomvolumen der Patientengruppe mit gutem Outcome betrug $55 \mathrm{ml}$, das der Gruppe mit schlechtem Outcome $58 \mathrm{ml}$. In der Patientengruppe mit kleineren Hämatomen ( $<56 \mathrm{ml})$ zeigten 35 Patienten (64\%) bei Entlassung einen guten Allgemeinzustand, während bei 20 Patienten $(36 \%)$ ein schlechter Zustand dokumentiert wurde. In der Patientengruppe mit größeren Hämatomen (>56 ml) befanden sich 30 Patienten $(60 \%)$ in gutem und 20 Patienten (40\%) in schlechtem Zustand bei Entlassung. Die Daten sind nochmals in Tab. 6 zusammengefasst.

Wir konnten keinen signifikanten Zusammenhang zwischen der Katheterlage und dem Outcome der Patienten bei Entlassung feststellen (lineare Abnahme, p=90). 
Tabelle 6: Zusammenhang zwischen Hämatomvolumina, Katheterlage und Patientenoutcome

\begin{tabular}{|l|l|l|}
\hline Outcome & Gut (GOS 3-5) & Schlecht (GOS 1-2) \\
\hline $\begin{array}{l}\text { Patientenanzahl } \\
\text { insgesamt }\end{array}$ & $69(66 \%)$ & $36(34 \%)$ \\
\hline $\begin{array}{l}\text { Mittlere initiale } \\
\text { Hämatomvolumen }\end{array}$ & $55 \mathrm{ml}$ & $58 \mathrm{ml}$ \\
\hline $\begin{array}{l}\text { Kleinere initiale Hämatomvo- } \\
\text { lumina (<56 ml) }\end{array}$ & $35(64 \%)$ & $20(36 \%)$ \\
\hline $\begin{array}{l}\text { Größere initiale } \\
\text { Hämatomvolumina (>56 ml) }\end{array}$ & $30(60 \%)$ & $20(40 \%)$ \\
\hline Katheterlage zentral & $43(62 \%)$ & $26(38 \%)$ \\
\hline Katheterlage mit RE $>\mathbf{0 , 7}$ & $22(63 \%)$ & $14(37 \%)$ \\
\hline
\end{tabular}

\subsection{Ergebnisse der qualitativen Analyse}

Wir konnten zwei verschiedene Verhaltensmuster der Hämatomlyse bei Patienten mit zentraler Katheterlage entlang des längsten Hämatomdurchmessers identifizieren. Einerseits konnten wir eine gleichmäßiger verlaufende Volumenreduktion des Hämatoms beobachten $(42 / 69,61 \%)$, andererseits ließ sich eine primäre Volumenreduktion an der Katheterspitze in Nähe der Katheteröffnungen feststellen (27/69, 39\%). Bei randständiger Katheterlage wurde diese Volumenreduktion an den Katheteröffnungen ubiquitär beobachtet. In diesen Fällen fanden wir auch öfter ein im Zeitverlauf der Lyse entstandenes Residualhämatom ohne Kontakt zu den Katheteröffnungen. Abb. 10 und Abb. 11 zeigen beispielhaft die Schemata der Volumenreduktion bei zentraler und randständiger Katheterlage. 


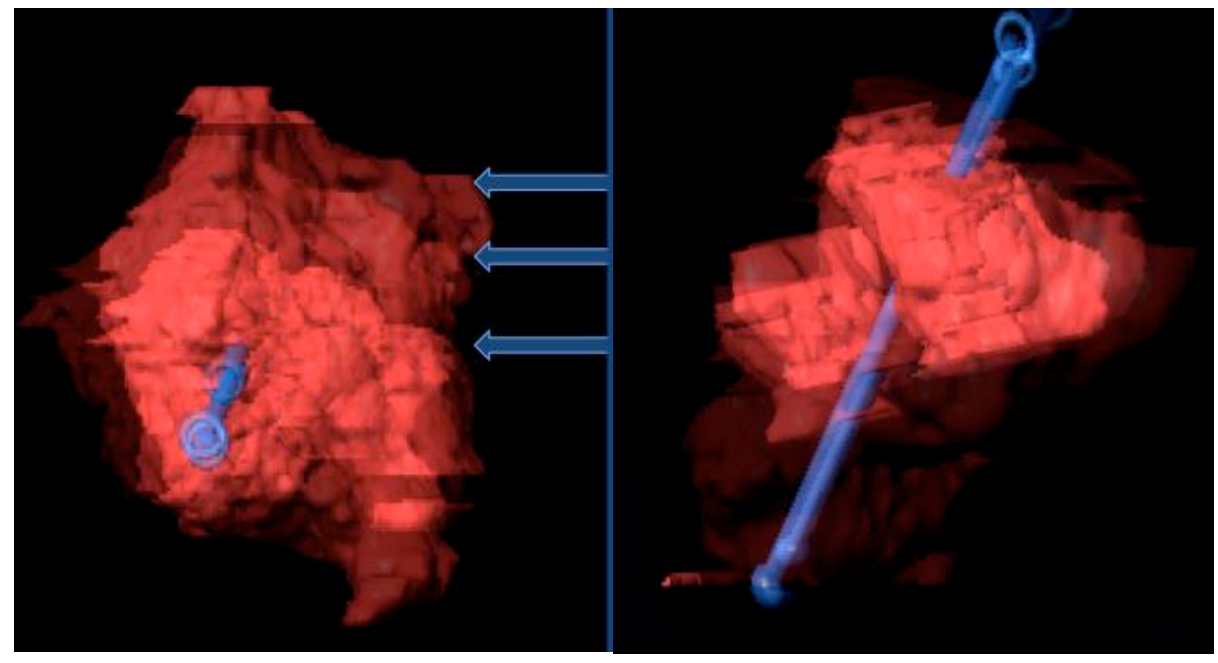

Abbildung 10: Beispielhaft die RVR eines Hämatoms unter Lysetherapie mit zentraler Katheterlage.

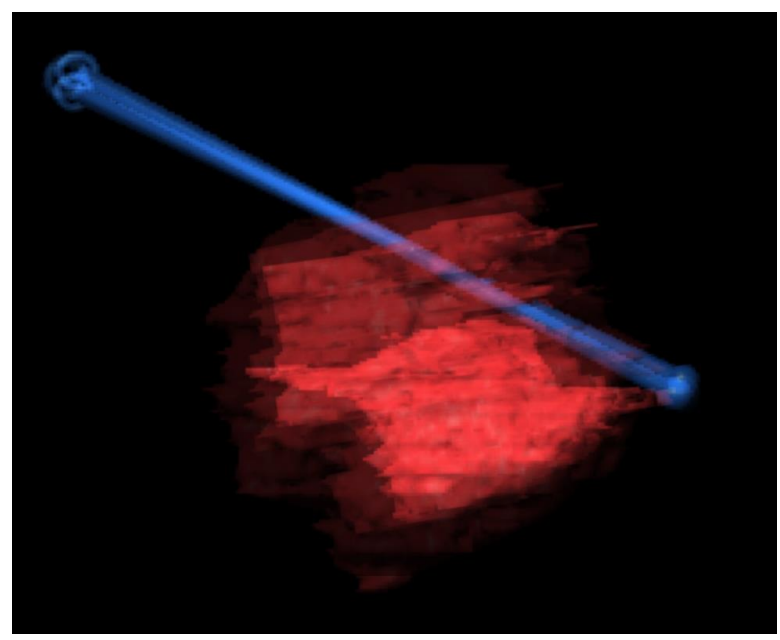

Abbildung 11: Beispielhaft die RVR bei randständiger Katheterlage. 


\section{Diskussion}

\subsection{Allgemeine Diskussion}

Die minimalinvasive Chirurgie mittels Katheteranlage und rtPA-Applikation zur Hämatomlyse ist eine sichere und bereits in einigen Zentren etablierte Methode zur Behandlung von Patienten mit spontaner ICB (Morgan et al. 2008a; Newell et al. 2011). Das Hauptziel des Verfahrens ist eine effektive, schnelle und sichere Hämatomlyse, um sekundäre Hirnschädigungen zu verhindern oder zumindest zu verringern.

Auf Grundlage von tierexperimentellen und klinischen Studien wird suggeriert, dass 5070\% der Hämatomvolumenreduktion durch eine fibrinolytische Therapie innerhalb von zwei Tagen erreicht wird. Es gibt Bedenken, dass dieser Zeitraum für eine effektive Verringerung der sekundären Hirnschädigung zu lang ist. Die mikrochirurgische Hämatomreduktion ist hingegen eine schnellere und effektivere Methode zur Hämatomevakuation. Ein Vergleich zwischen chirurgischer und konservativer Behandlung (STICH) konnte hingegen der Erwartung keine signifikanten Unterschiede nachweisen. Daher kann die mikrochirurgische Therapie trotz schnellerer Hämatomreduktion nicht als bessere Alternative zur fibrinolytischen Therapie gewertet werden (Mendelow et al. 2013).

Um die Effektivität der Lysetherapie zu untersuchen, fokussierten wir uns im Rahmen dieser Studie auf einen möglichen Einfluss der Katheterlage auf das Outcome der Patienten. Die Autoren der MISTIE-Studien gehen, in Übereinstimmung mit anderen Autoren vorheriger nichtrandomisierter Studien, davon aus, dass die Lage des Katheters innerhalb des größten Durchmessers des Hämatoms ideal für eine effektive Volumenreduktion ist und folglich angestrebt werden sollte (Rohde et al. 2000; Thiex et al. 2004).

Nach unserem Wissenstand ist die vorgelegte Arbeit die erste Studie, die sich der Fragestellung in Bezug auf die Katheterlage widmet. Hierzu haben wir die cCT-Aufnahmen von 105 Patienten mit ICBs, die minimalinvasiv via Katheteranlage mit anschließender Lysetherapie durch rtPA behandelt wurden, ausgewertet und retrospektiv analysiert. Die Hypothese, dass es einen Zusammenhang zwischen der Katheterlage und der Volumenreduktion und somit einer effektiveren Hämatomlyse gibt, konnte nicht bestätigt werden. 
Weiterführend konnte bereits in mehreren Studien ein Zusammenhang zwischen Hämatomvolumen und Outcome der Patienten mit spontaner ICB nachgewiesen werden (Broderick et al. 1993; Schaller et al. 1995; Wang et al. 2014). In unserer Studie haben wir die Behauptung jedoch nicht bestätigen können.

Im Folgenden sollen die Ergebnisse dieser Studie diskutiert, verschiedene Therapiemöglichkeiten sowie deren Vor- und Nachteile erläutert und Limitationen der vorliegenden Studie aufzeigt werden. 


\subsection{Der Einfluss der Katheterlage auf die Hämatomlyse}

Es wird konstatiert, dass die zentrale Lage entlang des größten Hämatomdurchmessers nach minimalinvasiver Operation mit intrahämatomaler Katheteranlage und rtPAApplikation essentiell für die effektive Lyse ist. Dem zugrunde liegt die Vermutung, dass die Öffnungen des Katheters auf diese Weise optimal in Relation zum Hämatom platziert werden und so eine homogene rtPA-Verteilung und effektive Aspiration gewährleisten (Maciunas et al. 1996).

Um eine zentrale Katheterlage zu erreichen, müssen des Öfteren Eintrittspunkte durch kosmetisch ungünstige oder operativ unvorteilhafte Regionen gewählt werden. Es kommt zum Beispiel vor, dass für die Trepanation ein Eintrittspunkt oberhalb der Augenbrauen erforderlich ist. Auch kann es notwendig sein, den Katheter durch den Sinus frontalis in das Hirnparenchym einzuführen. Der Durchtritt durch den Sinus erhöht allerdings das Risiko für eine Keimverschleppung und somit konsekutiv für Infektionen.

Folglich wäre es für die Patienten vorteilhaft, wenn nachgewiesen werden könnte, dass die zentrale Katheterlage keinen entscheidenden Faktor für die Effektivität der Hämatomlyse darstellt. In diesem Fall würden auch unnötige Zeitverzögerungen durch Neuimplantationen mit wiederholtem Komplikationsrisiko vermieden werden.

In unserer Studie fanden wir keinen signifikanten Zusammenhang zwischen der Hämatomvolumenreduktion und der Katheterlage. Diverse Faktoren gilt es bei der Interpretation dieser Ergebnisse zu berücksichtigen. Zum einen lagen nur vier von 105 Kathetern randständig. Folglich ist die Stichprobe zu klein, um signifikante Rückschlüsse zuzulassen. Zum anderen deuten unsere qualitativen Ergebnisse daraufhin, dass bei randständiger Katheterlage des Öfteren ein Residualhämatom ohne Kontakt zur Katheterspitze bestehen bleibt, es also nicht zu einer vollständigen Lyse des Hämatoms kommt. Es ist also fraglich, ob sich das rtPA weitreichend genug im Hämatom verteilen kann, wenn dieses nicht gänzlich gegenüber den Katheteröffnungen exponiert wird. Auch ließ sich bei zentraler Katheterlage eine gleichmäßigere Reduktion des Hämatoms beobachten als bei einer randständigen Lage. Hier kann sich das rtPA mutmaßlich besser verteilen und so für eine gleichmäßigere Lyse sorgen.

Des Weiteren zeigte sich in den Auswertungen der cCT-Aufnahmen eine schnellere Reduktion des Hämatomvolumens im Bereich der Katheteröffnungen. Auch dieser 
Aspekt spricht dafür, dass ein Kontakt zwischen den Katheteröffnungen und dem Hämatom während der gesamten Lysetherapie sichergestellt werden sollte, um diese optimal zu gewährleisten. Berücksichtigt man diese Ergebnisse, könnte es bei größeren Hämatomen zusätzlich von Vorteil sein, Katheter mit mehreren Öffnungen zu verwenden.

Theoretisch sprechen also einige Punkte für das Beibehalten der zentralen Katheterlage, auch wenn wir in dieser Arbeit keinen signifikanten Unterschied in der Volumenreduktion feststellen konnten. Dies müsste anhand weiterer Studien mit größeren Stichproben - insbesondere mit einer randständigen Katheterlage - ermittelt werden.

\subsection{Der Einfluss der Katheterlage und des Hämatomvolumens auf das Patientenoutcome}

Wir untersuchten weiterhin, ob es einen signifikanten Zusammenhang zwischen der Katheterlage und dem Patientenoutcome gibt. Insgesamt hatten 62\% der Patienten mit zentraler $(\mathrm{RE}<0,7)$ und $63 \%$ der Patienten mit weniger zentraler $(\mathrm{RE}>0,7)$ Katheterlage ein gutes Outcome bei Entlassung. Wir fanden also keine signifikante Korrelation zwischen der Katheterlage und dem Patientenoutcome.

Broderick et al. konnten 1993 einen Zusammenhang zwischen dem initialen Hämatomvolumen und dem Patientenoutcome feststellen. Sie werteten retrospektiv die Daten von 188 Patienten aus, deren ICB-Volumen sie in $<30 \mathrm{ml}, 30-60 \mathrm{ml}$ und $>60 \mathrm{ml}$ einteilten. Das Outcome im Sinne der Morbidität und 30-Tages-Mortalität wurde mit wachsendem Volumen der Hämatome signifikant schlechter. Sie werteten dementsprechend die initiale ICB-Größe als unabhängigen Prädiktor für das Patientenoutcome (Broderick et al. 1993). Von den Autoren Wang et. al wurde dies 2014 nochmals durch eine retrospektive Studie mit 106 eingeschlossenen Patienten bestätigt. Auch in dieser Studie war die Hämatomgröße ein prädiktiver Faktor für das Patientenoutcome (Wang et al. 2014). Beim ICH-Score, welcher zur einheitlichen Risikoabwägung der 30-Tages-Mortalität verwendet wird, ist das Hämatomvolumen ebenfalls ein entscheidender Faktor. Das Hämatomvolumen von $>30 \mathrm{ml}$ wird mit einem Punkt bewertet und gilt als ein negativer prognostischer Faktor (Hemphill et al. 2001). 
Wir konnten innerhalb unserer Stichprobe keine Korrelation zwischen dem ICBVolumen und dem Patientenoutcome feststellen. Ein Grund dafür könnte sein, dass die Hämatomvolumina unserer Patienten zwischen 30 und 143 ml lagen. Es gab also keinen Patienten, dessen Hämatomvolumen unter dem laut ICH-Score prognostisch relevanten Wert lag.

Hinsichtlich des Langzeit-Outcomes können wir auf Grund der retrospektiven Natur unserer Analyse keine Aussagen treffen, hierfür wäre die Evaluation im Rahmen einer prospektiven Studie erforderlich.

\subsection{Therapiemöglichkeiten der ICB}

Grundsätzlich kann eine ICB entweder konservativ oder operativ behandelt werden. Trotz mehrerer großangelegter Studien (STICH, STICH II), konnte kein signifikanter Vorteil einer chirurgischen Intervention gegenüber einer konservativen Behandlung nachgewiesen werden (Mendelow et al. 2005; Mendelow et al. 2013). An dem Studiendesign kritisch zu bewerten ist zum einen die Unterrepräsentation der minimalinvasiven Verfahren. Bei 75\% der operierten Patienten erfolgte eine Kraniotomie, lediglich 22\% wurden minimalinvasiv operiert. Zum anderen fand bei 25\% der Patienten ein Crossover von einer initial geplanten konservativen zu einer notfallmäßigen operativen Behandlung statt, da diese auf Grund ernstzunehmender klinischer Verschlechterung der Patienten als notwendig erachtet wurde.

$\mathrm{Ob}$ die Behandlung einer ICB konservativ oder operativ erfolgt, bleibt trotz einiger objektiver Kriterien individuell abzuwägen und obliegt letztendlich der Entscheidung der behandelnden Ärzte. Welche operative Technik gewählt wird, liegt nicht zuletzt auch an der Expertise der Operateure und den vorhandenen technischen Gegebenheiten. Im Folgenden möchte ich auf Vor- und Nachteile der verschiedenen operativen Techniken eingehen.

\subsubsection{Evakuation der ICB über eine Kraniotomie}

Die Vorteile einer Hämatomevakuation mittels Kraniotomie sind die gute Darstellbarkeit sowie die unmittelbare Entfernung des Hämatoms. Letzteres kann zum Beispiel bei einem infratentoriell lokalisierten Hämatom von Bedeutung sein. Das dort befindliche Hämatom kann Druck auf den Hirnstamm auslösen oder die Entstehung eines obstruk- 
tiven Hydrocephalus durch Verlegung des 4. Ventrikels und des Aquädukts verursachen und so eine rasche neurologische Verschlechterung hervorrufen. In diesem Fall wird laut Leitlinie eine zügige operative Hämatomevakuation mittels Kraniotomie dringend empfohlen (Hemphill et al. 2015).

Auch scheint das offene Verfahren gut für oberflächlich lokalisierte ICBs geeignet zu sein. In der STICH II-Studie konnte beispielsweise ein besseres Outcome für die Patienten gezeigt werden, deren Hämatome sich $1 \mathrm{~cm}$ unterhalb des Kortex befanden, im Vergleich zu einer chirurgischen Intervention bei Patienten mit tief sitzenden Hämatomen (Mendelow et al. 2005). Daraus ergibt sich ein Nachteil der Kraniotomie: Für die tiefen ICBs muss sich der Operateur zunächst seinen Weg durch die weiße Substanz und das intakte Hirnparenchym bahnen, wobei dieses verletzt werden und so zum Beispiel das Risiko für postoperative Infarkte, zerebrale Ödeme, neurologische Defizite und epileptische Anfälle erhöht werden kann (Ding et al. 2015).

\subsubsection{Minimalinvasive Techniken}

Es wird vermutet, dass minimalinvasive Techniken bei tiefen ICBs von Vorteil sind, hier wird das gesunde Hirnparenchym weniger geschädigt und so das Risiko für Folgeschäden minimiert. Es wurden in unserer Studie 59 tief und 46 lobär lokalisierte ICBs minimalinvasiv mit rahmenloser Stereotaxie therapiert.

Es wurde zum einen die Katheteranlage mittels Navigationspointer, Gelenkarm und Hülse und zum anderen mittels präregistriertem Stylet durchgeführt. Rahmengestützte Verfahren kamen nicht zum Einsatz. Folgend werden beide Verfahren diskutiert und deren Vor- und Nachteile eruiert.

\subsubsection{Rahmengestützte vs. rahmenlose Stereotaxie}

Rahmengestützte Verfahren gibt es seit den 50er Jahren. Der stereotaktische Rahmen wird hierbei an dem Kopf des Patienten befestigt. Daran angeschlossen ist ein herausnehm- und regulierbares Bogensystem, welches die Katheterpositionierung in der x-, yund z-Achse ermöglicht.

Eine etablierte Alternative ist die rahmenlose Stereotaxie mit Hilfe der Neuronavigation. Die digitalen Patientendaten werden vor der Operation in eine kraniale Navigationssoftware hochgeladen. So kann im OP-Saal der Zugang geplant werden bevor eine Inzision vorgenommen wird. Während der Operation werden die Instrumente in Echt- 
zeit verfolgt und dabei deren Position im Verhältnis zu den Patientendaten angezeigt, sodass das Risiko für Gewebeverletzungen minimiert werden kann.

Beide Vorgehensweisen wurden in mehreren Studien miteinander verglichen. Thiex et al. (2004) führten eine retrospektive Analyse bei 126 Patienten durch, von denen 53 rahmengestützt und 75 rahmenlos operiert wurden. Hinsichtlich einer effektiven Hämatomreduktion sowie dem klinischen Outcome wurden keine signifikanten Unterschiede gefunden. Allerdings war das Risiko einer Fehllage des Katheters bei der rahmenlosen Stereotaxie erhöht (Thiex et al. 2004). Eine weitere Studie verglich beide Techniken retrospektiv bei 30 Patienten mit supratentorieller tiefsitzender ICB und der Applikation von Urokinase als Fibrinolytikum (15 rahmengestützt, 15 rahmenlos). Die Autoren bewerteten beide Techniken als gleichsam effektiv, präzise, schnell und sicher, inklusive eines niedrigen Nachblutungsrisikos (Kim et al. 2007).

Rohde et al. (2000) postulierten eine Verkürzung der Operationsdauer und damit auch einen Rückgang der assoziierten Kosten bei Verwendung der rahmenlosen Stereotaxie. Als weiteren Vorteil beschrieben sie die größere Bandbreite der selektierbaren Trajektorien gegenüber der rahmengestützten Stereotaxie (Rohde et al. 2000). Um die Katheteranlage in rahmenlosen Techniken präziser zu gestalten, wurde eine neue Methode zur Katheterplatzierung entwickelt - das präregistrierte Stylet (s. u.).

\subsubsection{Hülse vs. Stylet}

In unserer Studie wurde zur Hämatomevakuation die rahmenlose Stereotaxie verwendet. Hierbei gab es zwei Methoden, die bereits 2014 von der Göttinger Forschungsgruppe verglichen wurden. In der ersten Methode erfolgt die Katheterplatzierung mit Hilfe einer Kombination aus Pointer-geführter Neuronavigation und Gelenkarm, welcher für die Einhaltung der zuvor berechneten Trajektorie erforderlich ist. Der Katheter wird hierbei über eine Hülse eingeführt. In der zweiten Methode wird ein präregistriertes Stylet verwendet, in welches sich der Katheter einsetzen lässt. Die Katheterspitze lässt sich so direkt mittels der präoperativ ermittelten Trajektorie in dem Hämatom platzieren. Der Vergleich beider Methoden anhand eines Patientenkollektivs von 89 Patienten (50 Hülse und 39 Stylet) zeigte, dass die Platzierung des Katheters mittels Stylet genauer war, das heißt, der RE war im Gesamtergebnis signifikant kleiner $(\mathrm{p}=0,0018)$. Die Autoren plädierten demnach für die dauerhafte Verwendung des Stylets anstatt der Pointer-Gelenkarm-Kombination (Malinova et al. 2014). 
In weiterführenden Studien müsste die rahmengestützte Technik mit der Verwendung eines Stylets verglichen werden, um das Risiko einer Katheterfehllage in Abhängigkeit von der gewählten Methode evaluieren zu können.

\subsection{Lysetherapie}

Für die Hämatomlyse können verschiedene Fibrinolytika verwendet werden, neben rtPA kommen auch Urokinase (urokinase type plasminogen activor, $u \mathrm{P} A$ ) und Streptokinase (SK) zum Einsatz. Zudem wird derzeit die ultraschallgesteuerte Thrombolyse getestet und versuchsweise eingesetzt (Masomi-Bornwasser et al. 2017).

\subsubsection{Alteplase (tPA)}

Im Rahmen dieser Studie haben wir die Daten von Patienten ausgewertet, deren ICBs über eine minimalinvasive Katheteranlage, gefolgt von einer Lyse des Hämatoms mit rtPA, behandelt wurden. Bei rtPA handelt es sich um gentechnisch hergestelltes tPA, ein Glykoprotein, welches sich im menschlichen Körper an den Fibrin-PlasminogenKomplex bindet und so die Konversion von Plasminogen zu Plasmin katalysiert. Es hat eine Halbwertszeit (HWZ) von 5 min und wird größtenteils über die Leber metabolisiert (Collen et al. 1989).

Die gute Dosierbarkeit, basierend auf der kurzen Halbwertszeit, und die hohe fibrinolytische Potenz führten schnell zu einem breiten Einsatzgebiet von rtPA, zum Beispiel in der Therapie von Lungenarterienembolien, ischämischen Schlaganfällen und akuten Myokardinfarkten (Gulba et al. 1996) sowie bei der Lyse von ICBs.

In der Literatur findet man vermehrt Hinweise auf eine neurotoxische Wirkung von rtPA. Chen et al. führten 1997 Tierexperimente an Hippocampi von Mäusen durch. Die Forscher fanden heraus, dass das durch rtPA aktivierte Plasmin über eine Proteolyse die neuronale extrazelluläre Matrix sowie das Laminin in der Basalmembran neuronaler Zellen zerstört, was einen konsekutiven Zelluntergang zur Folge hat (Chen und Strickland 1997). Rohde et al. (2002) wiesen an Schweinemodellen die Entwicklung eines späten PHE nach Lysetherapie mit rtPA nach und schlossen so auf hirngewebsschädigende und inflammatorische Eigenschaften des Fibrinolytikums (Rohde et al. 2002). 
In den bereits erwähnten MISTIE I- und MISTIE II-Studien wurde u. a. die Neurotoxizität mit Hilfe der postoperativen PHE-Entwicklung nach einer rtPA-Anwendung bei ICBs überprüft. Hierzu wurde in der chirurgischen Gruppe die rein stereotaktische mit der zusätzlich fibrinolytischen Gruppe verglichen. Die postoperativen PHEs zeigten keinen signifikanten Volumenunterschied. Folglich gingen die Autoren bei der rtPAInjektion in das Hämatom und Applikation geringer Dosen von keiner neurotoxischen Wirkung der Behandlung aus (Mould et al. 2013).

Trotz dieser Ergebnisse ist eine neurotoxische und inflammatorische Wirkung des rtPA somit wahrscheinlich. Es sollte daher bei dessen Anwendung beachtet werden, dass es ausschließlich intrahämatomal appliziert wird, damit es sich nicht in gesundes Hirnparenchym ausbreitet. Des Weiteren geht der Trend zur Anwendung geringerer Dosen, um potentielle Nebenwirkungen zu reduzieren.

\subsubsection{Dosierung des rtPA}

Die Wahl einer angemessenen Dosis des rtPA ist bislang nicht vereinheitlicht und könnte Auswirkungen auf die Effektivität der Hämatomlyse haben. In zuvor durchgeführten Studien wurde die Dosis dem größten Durchmesser des Hämatoms angepasst (Schaller et al. 1995; Thiex et al. 2004). In unserer Studie orientierten wir uns an dem TherapieProtokoll von Schaller et al. (1995). Wir verwendeten (bei einem mittleren Hämatomvolumen von $56 \mathrm{ml}$ ) $5 \mathrm{mg} \mathrm{rtPA}$ bei allen Patienten an drei aufeinanderfolgenden Tagen, sofern dies möglich war.

Kürzlich zeigte die Publikation einer Mainzer Forschungsgruppe, in der verschiedene rtPA-Dosierungen sowie Inkubationszeiten in einem neuen In-vitro-Modell getestet wurden, dass die Gabe von nur $1 \mathrm{mg}$ rtPA, unabhängig von der Größe des Hämatom, und einer Inkubationszeit von 15 min ausreichend für eine effektive Hämatomlyse war (Keric et al. 2017). Diese Ergebnisse müssen allerdings mit Vorsicht interpretiert werden, da in vivo die Wirkungen des rtPA durch diverse Faktoren des umliegenden Parenchyms beeinflusst werden, weshalb von den Autoren weiterführende Studien dringend empfohlen wurden. Dennoch könnten in der Zukunft die Lysetherapie-Protokolle und somit die Behandlung durch niedrige rtPA-Dosierung und Inkubationszeiten optimiert werden.

Auf unsere Fragestellung bezogen könnte sich eine veränderte rtPA-Dosis wiederum auf die Relevanz der zentralen Lage des Katheters auswirken. Würde man die Dosis 
verringern, könnte eine zentrale Lage essentiell sein, um eine ubiquitäre Verteilung des Fibrinolytikums dennoch zu gewährleisten. Bei Erhöhung der Dosis wäre eine randständige Lage ebenfalls von Nachteil, weil dann das Risiko für die Schädigung des umliegenden Hirnparenchyms steigen würde. Folglich müsste man bei Veränderung der rtPA-Dosis neue Evaluierungen anstreben.

\subsubsection{Der Einsatz von Sonothrombolyse}

An dem oben genannten Modell wurde ebenfalls der Einsatz einer ultraschallgesteuerten Thrombolyse untersucht. Durch die Bestrahlung wird das Hämatom zusätzlich aufgelockert und ist somit leichter aspirabel. Masomi-Bornwasser et al. (2017) versahen standardisierte Hämatome mit einem Katheter und evaluierten anschließend die Lyseraten bei alleiniger Drainage, isolierter rtPA-Gabe, alleinigem Ultraschall und bei einer Kombination aus rtPA und Ultraschall. Durch die Kombination von rtPA und Ultraschall wurden die höchsten Lyseraten erzielt, der Effekt galt auch für ältere Hämatome (Masomi-Bornwasser et al. 2017).

Newell et al. veröffentlichten bereits 2011 erste Ergebnisse zu ICBs, welche mit Sonothrombolyse behandelt wurden. Hier wurde bei neun Patienten stereotaktisch ein Katheter eingeführt, über dessen Spitze $24 \mathrm{~h}$ lang kontinuierlich Ultraschallwellen mit einer Reichweite von 3-4 cm ausgestrahlt wurden. Ziel dieser Studie war die Testung des Ultraschallkatheters in der Anwendung bei menschlichen ICBs, bezogen auf die therapieassoziierte Sicherheit und Durchführbarkeit. Die Autoren zeigten sich hinsichtlich der Ergebnisse optimistisch und ließen die Vermutung zu, dass sich der zusätzlich eingesetzte Ultraschall positiv auf die Effektivität der Volumenreduktion auswirkt. Verglichen wurden die Daten mit denen der CLEAR- und MISTIE-Studien. Dementsprechend wiesen die Autoren auf Limitationen in der Übertragung der Daten hin sowie auf notwendige weiterführende Studien mit größeren Stichproben (Newell et al. 2011).

Bezogen auf unsere Fragestellung wäre ein zusätzlich ultraschallbehandeltes Hämatom ebenfalls eine neue Ausgangslage. Das Hämatom könnte durch die Auflockerung noch besser aspirabel sein und eine zentrale Katheterlage daher essentiell für die Effizienz der Aspiration werden. 


\subsubsection{Urokinase (uPA)}

Das uPA wird derzeit als vielversprechende Alternative zum rtPA erforscht. Es ist ebenfalls ein Glykoprotein, welches in den Epithelzellen der Nierentubuli synthetisiert wird und die direkte Konversion von Plasminogen zu Plasmin katalysiert (Blasi 1993).

Tan et al. führten 2017 präklinische Tierversuche an Ratten durch, welchen zunächst autologes Blut in den Nucleus Caudatus injiziert wurde. Anschließend erfolgte die Applikation von entweder tPA, uPA oder Kochsalz. Die Ergebnisse zeigten einerseits, dass uPA eine Amelioration des PHE bewirkt und andererseits eine Verbesserung des klinischen Outcomes erzielt wurde (Tan et al. 2017). Ähnliche Ergebnisse brachte eine weitere Studie an Ratten hervor, in welcher die Applikation von uPA und tPA in das Ventrikelsystem bei IVBs getestet wurde. Während beide effizient das Blutvolumen reduzierten, wurde nur nach uPA-Gabe eine signifikante Verbesserung des funktionellen Outcomes erzielt. Die Autoren vermuten als Grund eine reduzierte inflammatorische und neurotoxische Wirkung des uPA im Vergleich zu tPA (Gaberel et al. 2014).

Im Jahr 2017 wurden die Ergebnisse einer retrospektiven klinischen Studie mit 86 Probanden veröffentlicht, die erstmalig den Einsatz von uPA und tPA bei der Lysetherapie von spontanen ICBs in Basalganglien direkt verglichen hat. Zwar war das Residualvolumen in der uPA-Gruppe niedriger als in der tPA-Gruppe und das PHE in der tPAGruppe leicht größer als bei der uPA-Gruppe, jedoch waren die Unterschiede statistisch nicht signifikant. Aus diesem Grund erfolgte die Schlussfolgerung, dass beide Fibrinolytika gleichsam effizient und sicher bei der Lysetherapie tief sitzender ICBs sind (Li et al. 2017).

Der Bedarf an weiteren, großangelegten experimentellen und klinischen Studien ist also vorhanden, um die konstatierten Vorteile einer Lysetherapie mit uPA zu untermauern.

\subsubsection{Streptokinase (SK)}

Ein weiteres Fibrinolytikum, welches über den Lysekatheter in das Hämatom appliziert werden kann, ist die Streptokinase (SK). Im menschlichen Körper von $\beta$ hämolysierenden Streptokokken ausgeschieden, bildet es mit Plasminogen einen Aktivatorkomplex, der Plasminogen zu Plasmin aktiviert (Lijnen und Collen 1986).

Von den drei Fibrinolytika ist die SK das günstigste Präparat und hat durch ihre lange in vivo HWZ eine große therapeutische Effektivität. Ein erheblicher Nachteil ist allerdings 
ihre Immunogenität, welche bei wiederholten Anwendungen oder nach stattgehabter Streptokokkeninfektion zu anaphylaktischen Reaktionen führen kann (Lee 1995).

Im Jahr 1997 wurde die Lysetherapie von ICBs mittels Streptokinase von Tzaan et al. an einem Patientenkollektiv von zwölf Patienten mit hypertensiver ICB getestet und ebenfalls als eine sichere Methode ohne schwerwiegende Nebenwirkungen deklariert (Tzaan et al. 1997).

In einer Studie von Bernotas et al. (2017) wurden 58 Patienten mit tiefsitzenden ICBs minimalinvasiv operiert und beide Fibrinolytika je nach Verfügbarkeit angewendet, wobei 45 der Patienten mit Streptokinase und zehn Patienten mit rtPA lysiert wurden. Es konnten keine signifikanten Unterschiede festgestellt werden, weder hinsichtlich der durchschnittlichen Hämatomvolumenreduktion, noch bezogen auf die Komplikationsrate (Bernotas et al. 2017). 


\subsection{Weitere Faktoren, die mögliche Auswirkungen auf die Effektivität der Lysetherapie haben}

\subsubsection{Zeitpunkt der Therapie}

In unserer Studie wurde der Eingriff innerhalb von $24 \mathrm{~h}$ nach Symptombeginn durchgeführt, da die rtPA-Applikation zeitgerecht nach der Diagnosestellung erfolgen sollte, bevor sich das Hämatom organsiert und verfestigt hat. Der beste Zeitpunkt für einen operativen Eingriff ist aber weiterhin umstritten (Hemphill et al. 2015). Wird die Operation innerhalb kürzester Zeit eingeleitet (innerhalb von $4 \mathrm{~h}$ nach Symptombeginn), so wurde 2001 eine erhöhte Chance auf Nachblutungen von Morgenstern et al. beschrieben (Morgenstern et al. 2001). Eine 2012 veröffentlichte Metaanalyse, in welche insgesamt 2186 Patienten aus acht Studien eingeschlossen wurden, zeigte, dass das Outcome verbessert wurde, wenn die Operation in einem Zeitrahmen von $8 \mathrm{~h}$ nach dem Blutungsereignis erfolgte (Gregson et al. 2012).

\subsection{Limitationen der Studie}

Die Limitationen der Studie liegen zum einen in ihrer retrospektiven Natur und zum anderen in der relativ kleinen Anzahl der Patienten welche inkludiert wurden. Zwar zählt die Studie mit 105 rekrutierten Patienten zu den größeren Studien, welche sich mit der fibrinolytischen Behandlung von ICBs auseinandersetzt, dennoch reicht die Probandenzahl nicht aus, um feine Unterschiede in der Volumenreduktion in Relation zur Katheterlage herauszuarbeiten, wie sie durch unsere qualitative Analyse zu vermuten sind. Hierbei ist insbesondere der Anteil an Patienten mit randständiger Katheterlage (4/105) viel zu gering, als dass sich signifikante Rückschlüsse ziehen lassen könnten.

Für die Messung der Volumina der ICBs verwendeten wir die Software der Firma BrainLab $^{\circ}$. In diesem Programm wird eine sogenannte smart brush verwendet, die alle zusammenhängenden Strukturen markiert, welche die gleiche Houndsfield-Einheit besitzen. Daraus ergibt sich das Risiko einer möglichen Ungenauigkeit bei der ICBMessung, da möglicherweise nicht mehr zum Hämatom gehörendes Gewebe fälschlich markiert worden ist. Allerdings relativieren sich die Auswirkungen auf das Ergebnis, wenn man bedenkt, dass wir alle ICBs mit dem gleichen Verfahren bearbeiteten haben. 
Zudem muss als mögliche Fehlerquelle genannt werden, dass die Messungen der Hämatomgröße (also der Vektoren A, B, C und D) von menschlicher Hand am Computer durchgeführt wurden. Das Programm errechnete anschließend anhand dieser manuellen Messungen das Volumen. Die Wahrscheinlichkeit für Fehlmessungen ist somit naturgemäß größer als bei einer rein digitalen Berechnung der Volumina.

Für die volumetrischen Messungen der Hämatome haben wir cCT-Datensätze verwendet. Anzumerken sei in diesem Zusammenhang, dass für die Berechnung von Volumina MRT-Bilder präziser sind. Ein weiterer Vorteil der MRT-Bildgebung ist, dass sie sensitiver bei der Detektion von Ödemen ist. Um folglich exaktere Volumenmessungen vollziehen zu können und die Möglichkeit der PHE-Messung zu gewinnen, sollte für zukünftige Studien der Einsatz von MRT-Material in Erwägung gezogen werden. 


\section{$5 \quad$ Zusammenfassung}

Die optimale Behandlung einer ICB ist seit langer Zeit Gegenstand kontroverser Debatten und diverser wissenschaftlicher Studien. Eine Behandlungsoption ist die minimalinvasive Therapie mittels Katheteranlage und rtPA-Applikation für die Hämatomlyse mit anschließender Hämatomdrainage. Es ist ein relativ neues Verfahren und wurde gerade in einer großen randomisierten Studie (MISTIE III) untersucht. Für dieses Verfahren wurde bislang angenommen, dass eine zentrale Katheterlage entlang des größten Hämatomdurchmessers essentiell für die Effektivität der Hämatomlyse ist. Bisher fehlten aber Studien, welche diese Vermutung verifizieren konnten. Wir verglichen daher in unserer Studie die Effektivität der Hämatomlyse, indem wir die relative Volumenreduktion (RVR) bei zentraler und randständiger Katheterlage errechneten und analysierten. Für die Evaluation der Katheterlage bestimmten wir den relative error (RE), welcher die Abweichung des eingesetzten Katheters zur optimalen Katheterlage beschreibt. Zusätzlich versuchten wir anhand der cCT-Aufnahmen Muster in der Hämatomlyse bei verschiedenen Katheterpositionen zu ermitteln. Das postoperative Outcome der Patienten wurde mit der Glasgow-Outcome-Skala bestimmt.

Insgesamt wurden 105 Patienten mit ICB in unsere Studie eingeschlossen. Wir fanden innerhalb unserer Stichprobe keine Korrelation zwischen Katheterlage und RVR. In der qualitativen Analyse beobachteten wir eine symmetrischere RVR des Hämatoms und eine schnellere Hämatomlyse an den Öffnungen der Katheterspitze. Bezüglich des Patientenoutcomes konnten wir ebenfalls keine Korrelation zur Katheterlage feststellen.

Die Effektivität der Hämatomlyse nach rtPA-Gabe ist somit innerhalb unserer Stichprobe nicht signifikant abhängig von der Lage des Katheters. 


\section{$6 \quad$ Literaturverzeichnis}

Abbott RD, Yin Y, Reed DM, Yano K (1986): Risk of stroke in male cigarette smokers. N Engl J Med 315, 717-720

Anderson CS, Heeley E, Huang Y, Wang J, Stapf C, Delcourt C, Lindley R, Robinson T, Lavados P, Neal B et al. (2013): Rapid blood-pressure lowering in patients with acute intracerebral hemorrhage. N Engl J Med $\underline{368}$, 2355-2365

Ariesen MJ, Claus SP, Rinkel GJ, Algra A (2003): Risk factors for intracerebral hemorrhage in the general population: a systematic review. Stroke 34, 2060-2065

Auer LM, Deinsberger W, Niederkorn K, Gell G, Kleinert R, Schneider G, Holzer P, Bone G, Mokry M, Korner E et al. (1989): Endoscopic surgery versus medical treatment for spontaneous intracerebral hematoma: a randomized study. J Neurosurg $\underline{70,}$ 530-535

Balami JS, Buchan AM (2012): Complications of intracerebral haemorrhage. Lancet Neurol 11, 101-118

Bernotas G, Simaitis K, Bunevicius A, Tamasauskas A (2017): Safety and efficacy of stereotactic aspiration with fibrinolysis for deep-seated spontaneous intracerebral hemorrhages: A single-center experience. Medicina (Kaunas) 53, 303-309

Blasi F (1993): Urokinase and urokinase receptor: a paracrine/autocrine system regulating cell migration and invasiveness. Bioessays $\underline{15}, 105-111$

Broderick JP, Brott TG, Duldner JE, Tomsick T, Huster G (1993): Volume of intracerebral hemorrhage. A powerful and easy-to-use predictor of 30-day mortality. Stroke 24, 987-993 
Broderick JP, Diringer MN, Hill MD, Brun NC, Mayer SA, Steiner T, Skolnick BE, Davis SM, Recombinant Activated Factor VIIIHTI (2007): Determinants of intracerebral hemorrhage growth: an exploratory analysis. Stroke 38, 1072-1075

Brott T, Thalinger K, Hertzberg V (1986): Hypertension as a risk factor for spontaneous intracerebral hemorrhage. Stroke 17, 1078-1083

Brott T, Broderick J, Kothari R, Barsan W, Tomsick T, Sauerbeck L, Spilker J, Duldner J, Khoury J (1997): Early hemorrhage growth in patients with intracerebral hemorrhage. Stroke 28, 1-5

Carney N, Totten AM, O'Reilly C, Ullman JS, Hawryluk GW, Bell MJ, Bratton SL, Chesnut R, Harris OA, Kissoon N et al. (2017): Guidelines for the Management of Severe Traumatic Brain Injury, Fourth Edition. Neurosurgery 80, 6-15

Catto AJ, Kohler HP, Bannan S, Stickland M, Carter A, Grant PJ (1998): Factor XIII Val 34 Leu: a novel association with primary intracerebral hemorrhage. Stroke 29 , 813816

Chen ZL, Strickland S (1997): Neuronal death in the hippocampus is promoted by plasmin-catalyzed degradation of laminin. Cell $191,917-925$

Collen D, Lijnen HR, Todd PA, Goa KL (1989): Tissue-type plasminogen activator. A review of its pharmacology and therapeutic use as a thrombolytic agent. Drugs $\underline{38}$, 346388

Davis SM, Broderick J, Hennerici M, Brun NC, Diringer MN, Mayer SA, Begtrup K, Steiner T, Recombinant Activated Factor VIIIHTI (2006): Hematoma growth is a determinant of mortality and poor outcome after intracerebral hemorrhage. Neurology 66, $1175-1181$

Ding D, Przybylowski CJ, Starke RM, Sterling Street R, Tyree AE, Webster Crowley R, Liu KC (2015): A minimally invasive anterior skull base approach for evacuation of a basal ganglia hemorrhage. J Clin Neurosci 22, 1816-1819 
Dye JA, Dusick JR, Lee DJ, Gonzalez NR, Martin NA (2012): Frontal bur hole through an eyebrow incision for image-guided endoscopic evacuation of spontaneous intracerebral hemorrhage. J Neurosurg 117, 767-773

Fan YH, Mok VC, Lam WW, Hui AC, Wong KS (2004): Cerebral microbleeds and white matter changes in patients hospitalized with lacunar infarcts. J Neurol 251, 537541

Fang MC, Go AS, Chang Y, Hylek EM, Henault LE, Jensvold NG, Singer DE (2007): Death and disability from warfarin-associated intracranial and extracranial hemorrhages. Am J Med 120, 700-705

Fisher CM (1971): Pathological observations in hypertensive cerebral hemorrhage. J Neuropathol Exp Neurol 30, 536-550

Foerch C, Misselwitz B, Sitzer M, Steinmetz H, Neumann-Haefelin T, Hesse Stroke Study G (2008): The projected burden of stroke in the German federal state of Hesse up to the year 2050. Dtsch Arztebl Int 105, 467-473

Foulkes MA, Wolf PA, Price TR, Mohr JP, Hier DB (1988): The Stroke Data Bank: design, methods, and baseline characteristics. Stroke 19, 547-554

Gaberel T, Montagne A, Lesept F, Gauberti M, Lemarchand E, Orset C, Goulay R, Bertrand T, Emery E, Vivien D (2014): Urokinase versus Alteplase for intraventricular hemorrhage fibrinolysis. Neuropharmacology $\underline{85}, 158-165$

Garcia Rodriguez LA, Martin-Perez M, Hennekens CH, Rothwell PM, Lanas A (2016): Bleeding Risk with Long-Term Low-Dose Aspirin: A Systematic Review of Observational Studies. PLoS One 11, e0160046

Gregson BA, Broderick JP, Auer LM, Batjer H, Chen XC, Juvela S, Morgenstern LB, Pantazis GC, Teernstra OP, Wang WZ et al. (2012): Individual patient data subgroup meta-analysis of surgery for spontaneous supratentorial intracerebral hemorrhage. Stroke $\underline{43}, 1496-1504$ 
Group GBDNDC (2017): Global, regional, and national burden of neurological disorders during 1990-2015: a systematic analysis for the Global Burden of Disease Study 2015. Lancet Neurol 16, 877-897

Grunwald Z, Beslow LA, Urday S, Vashkevich A, Ayres A, Greenberg SM, Goldstein JN, Leasure A, Shi FD, Kahle KT et al. (2017): Perihematomal Edema Expansion Rates and Patient Outcomes in Deep and Lobar Intracerebral Hemorrhage. Neurocrit Care 26, 205-212

Gulba DC, Bode C, Runge MS, Huber K (1996): Thrombolytic agents--an overview. Ann Hematol 73 Suppl 1, S9-27

Hanley DF, Thompson RE, Muschelli J, Rosenblum M, McBee N, Lane K, Bistran-Hall AJ, Mayo SW, Keyl P, Gandhi D et al. (2016): Safety and efficacy of minimally invasive surgery plus alteplase in intracerebral haemorrhage evacuation (MISTIE): a randomised, controlled, open-label, phase 2 trial. Lancet Neurol 15, 1228-1237

Hanley DF, Lane K, McBee N, Ziai W, Tuhrim S, Lees KR, Dawson J, Gandhi D, Ullman N, Mould WA et al. (2017): Thrombolytic removal of intraventricular haemorrhage in treatment of severe stroke: results of the randomised, multicentre, multiregion, placebo-controlled CLEAR III trial. Lancet 389, 603-611

Hanley DF, Thompson RE, Rosenblum M, Yenokyan G, Lane K, McBee N, Mayo SW, Bistran-Hall AJ, Gandhi D, Mould WA et al. (2019): Efficacy and safety of minimally invasive surgery with thrombolysis in intracerebral haemorrhage evacuation (MISTIE III): a randomised, controlled, open-label, blinded endpoint phase 3 trial. Lancet $\underline{393}$, $1021-1032$

Hemphill JC, 3rd, Bonovich DC, Besmertis L, Manley GT, Johnston SC (2001): The ICH score: a simple, reliable grading scale for intracerebral hemorrhage. Stroke $\underline{32}, 891$ 897

Hemphill JC, 3rd, Greenberg SM, Anderson CS, Becker K, Bendok BR, Cushman M, Fung GL, Goldstein JN, Macdonald RL, Mitchell PH et al. (2015): Guidelines for the Management of Spontaneous Intracerebral Hemorrhage: A Guideline for Healthcare Professionals From the American Heart Association/American Stroke Association. Stroke 46, 2032-2060 
Huttner HB, Nagel S, Tognoni E, Kohrmann M, Juttler E, Orakcioglu B, Schellinger PD, Schwab S, Bardutzky J (2007): Intracerebral hemorrhage with severe ventricular involvement: lumbar drainage for communicating hydrocephalus. Stroke $\underline{38}, 183-187$

Jennett B, Bond M (1975): Assessment of outcome after severe brain damage. Lancet $\underline{1}$, 480-484

Kamel H, Navi BB, Nakagawa K, Hemphill JC, 3rd, Ko NU (2011): Hypertonic saline versus mannitol for the treatment of elevated intracranial pressure: a meta-analysis of randomized clinical trials. Crit Care Med 39, 554-559

Keric N, Masomi-Bornwasser J, Muller-Werkmeister H, Kantelhardt SR, Konig J, Kempski O, Giese A (2017): Optimization of Catheter Based rtPA Thrombolysis in a Novel In Vitro Clot Model for Intracerebral Hemorrhage. Biomed Res Int 2017, 5472936

Kidwell CS, Chalela JA, Saver JL, Starkman S, Hill MD, Demchuk AM, Butman JA, Patronas N, Alger JR, Latour LL et al. (2004): Comparison of MRI and CT for detection of acute intracerebral hemorrhage. JAMA 292, 1823-1830

Kim IS, Son BC, Lee SW, Sung JH, Hong JT (2007): Comparison of frame-based and frameless stereotactic hematoma puncture and subsequent fibrinolytic therapy for the treatment of supratentorial deep seated spontaneous intracerebral hemorrhage. Minim Invasive Neurosurg $\underline{50}, 86-90$

Kolominsky-Rabas PL, Sarti C, Heuschmann PU, Graf C, Siemonsen S, Neundoerfer B, Katalinic A, Lang E, Gassmann KG, von Stockert TR (1998): A prospective community-based study of stroke in Germany--the Erlangen Stroke Project (ESPro): incidence and case fatality at 1, 3, and 12 months. Stroke 29, 2501-2506

Lee HS (1995): How safe is the readministration of streptokinase? Drug Saf $\underline{13}$, 76-80

Li Y, Yang R, Li Z, Tian B, Zhang X, Wang J, Zheng L, Wang B, Li L (2017): Urokinase vs Tissue-Type Plasminogen Activator for Thrombolytic Evacuation of Spontaneous Intracerebral Hemorrhage in Basal Ganglia. Front Neurol 8, 371 
Lijnen HR, Collen D (1986): Molecular mechanisms of thrombolytic therapy. Haemostasis 16 Suppl 3, 3-15

Malinova V, Stockhammer F, Atangana EN, Mielke D, Rohde V (2014): Catheter placement for lysis of spontaneous intracerebral hematomas: is a navigated stylet better than pointer-guided frameless stereotaxy for intrahematomal catheter positioning? Transl Stroke Res $\underline{5}, 407-414$

Malinova V, Schlegel A, Rohde V, Mielke D (2017): Catheter placement for lysis of spontaneous intracerebral hematomas: does a catheter position in the core of the hematoma allow more effective and faster hematoma lysis? Neurosurg Rev $\underline{40}$, 397-402

Manno EM, Atkinson JL, Fulgham JR, Wijdicks EF (2005): Emerging medical and surgical management strategies in the evaluation and treatment of intracerebral hemorrhage. Mayo Clin Proc $\underline{80}$, 420-433

Masomi-Bornwasser J, Winter P, Muller-Werkmeister H, Strand S, Konig J, Kempski O, Ringel F, Kantelhardt SR, Keric N (2017): Combination of ultrasound and rtPA enhances fibrinolysis in an In Vitro clot system. PLoS One 12, e0188131

McMillan T, Wilson L, Ponsford J, Levin H, Teasdale G, Bond M (2016): The Glasgow Outcome Scale - 40 years of application and refinement. Nat Rev Neurol 12, 477-485

Mendelow AD, Gregson BA, Fernandes HM, Murray GD, Teasdale GM, Hope DT, Karimi A, Shaw MD, Barer DH, investigators S (2005): Early surgery versus initial conservative treatment in patients with spontaneous supratentorial intracerebral haematomas in the International Surgical Trial in Intracerebral Haemorrhage (STICH): a randomised trial. Lancet $\underline{365}, 387-397$

Mendelow AD, Gregson BA, Rowan EN, Murray GD, Gholkar A, Mitchell PM, Investigators SI (2013): Early surgery versus initial conservative treatment in patients with spontaneous supratentorial lobar intracerebral haematomas (STICH II): a randomised trial. Lancet 382, 397-408 
Morgan T, Zuccarello M, Narayan R, Keyl P, Lane K, Hanley D (2008a): Preliminary findings of the minimally-invasive surgery plus rtPA for intracerebral hemorrhage evacuation (MISTIE) clinical trial. Acta Neurochir Suppl 105, 147-151

Morgan T, Awad I, Keyl P, Lane K, Hanley D (2008b): Preliminary report of the clot lysis evaluating accelerated resolution of intraventricular hemorrhage (CLEAR-IVH) clinical trial. Acta Neurochir Suppl 105, 217-220

Morgenstern LB, Demchuk AM, Kim DH, Frankowski RF, Grotta JC (2001): Rebleeding leads to poor outcome in ultra-early craniotomy for intracerebral hemorrhage. Neurology $\underline{56}$, 1294-1299

Mould WA, Carhuapoma JR, Muschelli J, Lane K, Morgan TC, McBee NA, Bistran-Hall AJ, Ullman NL, Vespa P, Martin NA et al. (2013): Minimally invasive surgery plus recombinant tissue-type plasminogen activator for intracerebral hemorrhage evacuation decreases perihematomal edema. Stroke $\underline{44}$, 627-634

Mutlu N, Berry RG, Alpers BJ (1963): Massive Cerebral Hemorrhage. Clinical and Pathological Correlations. Arch Neurol $\underline{8}$, 644-661

Neuberger U, Mohlenbruch MA, Herweh C, Ulfert C, Bendszus M, Pfaff J (2017): Classification of Bleeding Events: Comparison of ECASS III (European Cooperative Acute Stroke Study) and the New Heidelberg Bleeding Classification. Stroke 48, 19831985

Newell DW, Shah MM, Wilcox R, Hansmann DR, Melnychuk E, Muschelli J, Hanley DF (2011): Minimally invasive evacuation of spontaneous intracerebral hemorrhage using sonothrombolysis. J Neurosurg 115, 592-601

Pascual AM, Lopez-Mut JV, Benlloch V, Chamarro R, Soler J, Lainez MJ (2007): Perfusion-weighted magnetic resonance imaging in acute intracerebral hemorrhage at baseline and during the 1 st and 2nd week: a longitudinal study. Cerebrovasc Dis $\underline{23}$, 613

Qureshi AI, Mohammad Y, Suri MF, Braimah J, Janardhan V, Guterman LR, Hopkins LN, Frankel MR (2001a): Cocaine use and hypertension are major risk factors for intracerebral hemorrhage in young African Americans. Ethn Dis 11, 311-319 
Qureshi AI, Tuhrim S, Broderick JP, Batjer HH, Hondo H, Hanley DF (2001b): Spontaneous intracerebral hemorrhage. N Engl J Med 344, 1450-1460

Rohde V, Rohde I, Reinges MH, Mayfrank L, Gilsbach JM (2000): Frameless stereotactically guided catheter placement and fibrinolytic therapy for spontaneous intracerebral hematomas: technical aspects and initial clinical results. Minim Invasive Neurosurg $\underline{43}, 9-17$

Rohde V, Rohde I, Thiex R, Ince A, Jung A, Duckers G, Groschel K, Rottger C, Kuker W, Muller HD et al. (2002): Fibrinolysis therapy achieved with tissue plasminogen activator and aspiration of the liquefied clot after experimental intracerebral hemorrhage: rapid reduction in hematoma volume but intensification of delayed edema formation. J Neurosurg 97, 954-962

Romero JM, Artunduaga M, Forero NP, Delgado J, Sarfaraz K, Goldstein JN, Gonzalez RG, Schaefer PW (2009): Accuracy of CT angiography for the diagnosis of vascular abnormalities causing intraparenchymal hemorrhage in young patients. Emerg Radiol $\underline{16}, 195-201$

Rosand J, Eskey C, Chang Y, Gonzalez RG, Greenberg SM, Koroshetz WJ (2002): Dynamic single-section CT demonstrates reduced cerebral blood flow in acute intracerebral hemorrhage. Cerebrovasc Dis 14, 214-220

Rost NS, Greenberg SM, Rosand J (2008): The genetic architecture of intracerebral hemorrhage. Stroke 39, 2166-2173

Ruff CT, Giugliano RP, Braunwald E, Hoffman EB, Deenadayalu N, Ezekowitz MD, Camm AJ, Weitz JI, Lewis BS, Parkhomenko A et al. (2014): Comparison of the efficacy and safety of new oral anticoagulants with warfarin in patients with atrial fibrillation: a meta-analysis of randomised trials. Lancet $\underline{383}, 955-962$

Sacco RL, Boden-Albala B, Gan R, Chen X, Kargman DE, Shea S, Paik MC, Hauser WA (1998): Stroke incidence among white, black, and Hispanic residents of an urban community: the Northern Manhattan Stroke Study. Am J Epidemiol 147, 259-268 
Sacco S, Marini C, Toni D, Olivieri L, Carolei A (2009): Incidence and 10-year survival of intracerebral hemorrhage in a population-based registry. Stroke $\underline{40}$, 394-399

Sadrzadeh SM, Anderson DK, Panter SS, Hallaway PE, Eaton JW (1987): Hemoglobin potentiates central nervous system damage. J Clin Invest 79, 662-664

Schaller C, Rohde V, Meyer B, Hassler W (1995): Stereotactic puncture and lysis of spontaneous intracerebral hemorrhage using recombinant tissue-plasminogen activator. Neurosurgery $36,328-333$

Schellinger PD, Fiebach JB, Hoffmann K, Becker K, Orakcioglu B, Kollmar R, Juttler E, Schramm P, Schwab S, Sartor K et al. (2003): Stroke MRI in intracerebral hemorrhage: is there a perihemorrhagic penumbra? Stroke 34, 1674-1679

Shoeb M, Fang MC (2013): Assessing bleeding risk in patients taking anticoagulants. J Thromb Thrombolysis 35, 312-319

Singer OC, Sitzer M, du Mesnil de Rochemont R, Neumann-Haefelin T (2004): Practical limitations of acute stroke MRI due to patient-related problems. Neurology $\underline{62}$, 18481849

Sturgeon JD, Folsom AR, Longstreth WT, Jr., Shahar E, Rosamond WD, Cushman M (2007): Risk factors for intracerebral hemorrhage in a pooled prospective study. Stroke 38, 2718-2725

SWITCH-Studie: https://clinicaltrials.gov/ct2/show/NCT02258919?cond= hemorrhage\&cntry $=\mathrm{CH} \& \mathrm{draw}=2 \& \mathrm{rank}=38$, Zugriff am 05.03.2020

Takebayashi S, Kaneko M (1983): Electron microscopic studies of ruptured arteries in hypertensive intracerebral hemorrhage. Stroke 14, 28-36

Tan Q, Chen Q, Niu Y, Feng Z, Li L, Tao Y, Tang J, Yang L, Guo J, Feng H et al. (2017): Urokinase, a promising candidate for fibrinolytic therapy for intracerebral hemorrhage. J Neurosurg 126, 548-557 
Teasdale G, Jennett B (1974): Assessment of coma and impaired consciousness. A practical scale. Lancet $\underline{2}, 81-84$

Teernstra OP, Evers SM, Lodder J, Leffers P, Franke CL, Blaauw G, Multicenter randomized controlled $\mathrm{t}$ (2003): Stereotactic treatment of intracerebral hematoma by means of a plasminogen activator: a multicenter randomized controlled trial (SICHPA). Stroke 34, 968-974

Thiex R, Rohde V, Rohde I, Mayfrank L, Zeki Z, Thron A, Gilsbach JM, Uhl E (2004): Frame-based and frameless stereotactic hematoma puncture and subsequent fibrinolytic therapy for the treatment of spontaneous intracerebral hemorrhage. J Neurol 251, 14431450

Tzaan WC, Lee ST, Lui TN (1997): Combined use of stereotactic aspiration and intracerebral streptokinase infusion in the surgical treatment of hypertensive intracerebral hemorrhage. J Formos Med Assoc 96, 962-967

van Asch CJ, Luitse MJ, Rinkel GJ, van der Tweel I, Algra A, Klijn CJ (2010): Incidence, case fatality, and functional outcome of intracerebral haemorrhage over time, according to age, sex, and ethnic origin: a systematic review and meta-analysis. Lancet Neurol $\underline{9}$, $167-176$

Vila-Corcoles A, Satue-Gracia E, Ochoa-Gondar O, de Diego-Cabanes C, Vila-Rovira A, Blade J, Bobe F, Casanova R, Jariod M, Reig R (2014): [Incidence and lethality of ischaemic stroke among people 60 years or older in the region of Tarragona (Spain), 2008-2011]. Rev Neurol 59, 490-496

Wada R, Aviv RI, Fox AJ, Sahlas DJ, Gladstone DJ, Tomlinson G, Symons SP (2007): CT angiography "spot sign" predicts hematoma expansion in acute intracerebral hemorrhage. Stroke $\underline{38}, 1257-1262$

Wang CW, Liu YJ, Lee YH, Hueng DY, Fan HC, Yang FC, Hsueh CJ, Kao HW, Juan CJ, Hsu HH (2014): Hematoma shape, hematoma size, Glasgow coma scale score and ICH score: which predicts the 30-day mortality better for intracerebral hematoma? PLoS One 9, e102326 
Webb AJ, Ullman NL, Mann S, Muschelli J, Awad IA, Hanley DF (2012): Resolution of intraventricular hemorrhage varies by ventricular region and dose of intraventricular thrombolytic: the Clot Lysis: Evaluating Accelerated Resolution of IVH (CLEAR IVH) program. Stroke 43, 1666-1668

Weir CJ, Murray GD, Adams FG, Muir KW, Grosset DG, Lees KR (1994): Poor accuracy of stroke scoring systems for differential clinical diagnosis of intracranial haemorrhage and infarction. Lancet 344, 999-1002

Woo D, Haverbusch M, Sekar P, Kissela B, Khoury J, Schneider A, Kleindorfer D, Szaflarski J, Pancioli A, Jauch E et al. (2004): Effect of untreated hypertension on hemorrhagic stroke. Stroke 35, 1703-1708

Xi G, Keep RF, Hoff JT (2006): Mechanisms of brain injury after intracerebral haemorrhage. Lancet Neurol $\underline{5}, 53-63$

Xu X, Zheng Y, Chen X, Li F, Zhang H, Ge X (2017): Comparison of endoscopic evacuation, stereotactic aspiration and craniotomy for the treatment of supratentorial hypertensive intracerebral haemorrhage: study protocol for a randomised controlled trial. Trials $\underline{18}, 296$

Zazulia AR, Diringer MN, Videen TO, Adams RE, Yundt K, Aiyagari V, Grubb RL, Jr., Powers WJ (2001): Hypoperfusion without ischemia surrounding acute intracerebral hemorrhage. J Cereb Blood Flow Metab 21, 804-810

Zheng J, Li H, Guo R, Lin S, Hu X, Dong W, Ma L, Fang Y, Xiao A, Liu M et al. (2014): Minimally invasive surgery treatment for the patients with spontaneous supratentorial intracerebral hemorrhage (MISTICH): protocol of a multi-center randomized controlled trial. BMC Neurol 14, 206 